\title{
Sustained Notch signaling in progenitors is required for sequential emergence of distinct cell lineages during organogenesis
}

\author{
Xiaoyan Zhu, ${ }^{1,7}$ Jie Zhang, ${ }^{1}$ Jessica Tollkuhn, ${ }^{1,2}$ Ryosuke Ohsawa, ${ }^{3}$ Emery H. Bresnick, ${ }^{4}$ \\ François Guillemot, ${ }^{5}$ Ryoichiro Kageyama, ${ }^{3}$ and Michael G. Rosenfeld ${ }^{1,6}$ \\ ${ }^{1}$ Howard Hughes Medical Institute, Department and School of Medicine, University of California at San Diego, La Jolla, \\ California 92093, USA; ${ }^{2}$ Biomedical Sciences Graduate Program, University of California at San Diego, La Jolla, California \\ 92093, USA; ${ }^{3}$ Institute for Virus Research, Kyoto University, Sakyo-ku, Kyoto, Japan; ${ }^{4}$ University of Wisconsin Medical \\ School, Madison, Wisconsin 53706, USA; ${ }^{5}$ Division of Molecular Neurobiology, National Institute for Medical Research, \\ London NW7 1AA, United Kingdom
}

\begin{abstract}
Mammalian organogenesis results from the concerted actions of signaling pathways in progenitor cells that induce a hierarchy of regulated transcription factors critical for organ and cell type determination. Here we demonstrate that sustained Notch activity is required for the temporal maintenance of specific cohorts of proliferating progenitors, which underlies the ability to specify late-arising cell lineages during pituitary organogenesis. Conditional deletion of $R b p-J$, which encodes the major mediator of the Notch pathway, leads to premature differentiation of progenitor cells, a phenotype recapitulated by loss of the basic helix-loop-helix (bHLH) factor Hes1, as well as a conversion of the late (Pit1) lineage into the early (corticotrope) lineage. Notch signaling is required for maintaining expression of the tissue-specific paired-like homeodomain transcription factor, Prop1, which is required for generation of the Pit1 lineage. Attenuation of Notch signaling is necessary for terminal differentiation in post-mitotic Pit1 ${ }^{+}$cells, and the Notch-repressed Pit1 target gene, Math3, is specifically required for maturation and proliferation of the GH-producing somatotrope. Thus, sustained Notch signaling in progenitor cells is required to prevent conversion of the late-arising cell lineages to early-born cell lineages, permitting specification of diverse cell types, a strategy likely to be widely used in mammalian organogenesis.
\end{abstract}

[Keywords: Notch; organogenesis; bHLH; Prop1; pituitary; precursor cells; differentiation]

Supplemental material is available at http://www.genesdev.org.

Received April 28, 2006; revised version accepted August 3, 2006.

Notch signaling is an evolutionarily conserved mechanism that regulates proliferation, apoptosis, cell fate determination, and morphogenesis in organisms ranging from nematodes to humans (for reviews, see Lewis 1998; Artavanis-Tsakonas et al. 1999|. Notch signaling is mediated by the interaction between the Notch receptor and its ligands Delta and Serrate. Both receptor and ligand are cell-surface transmembrane proteins that contain extracellular arrays of epidermal growth factor (EGF) repeats. Specific EGF repeats mediate direct interaction between ligand and receptor. Mammals have four Notch receptors (Notch1, Notch2, Notch3, and Notch4) and five ligands (Delta-like1, Delta-like3, Delta-like4 [homologs of Delta], and Jagged1 and Jagged2 [homologs of Serrate]). Upon ligand binding, Notch receptors undergo

Corresponding authors.

${ }^{6}$ E-MAIL mrosenfeld@ucsd.edu; FAX (858) 534-8180.

${ }^{7}$ E-MAIL xizhu@ucsd.edu; FAX (858) 534-8180.

Article is online at http://www.genesdev.org/cgi/doi/10.1101/gad.1444706. successive proteolytic cleavages that lead to the release of the Notch intracellular domain (ICD) and subsequent nuclear translocation. Once in the nucleus, the ICD forms a complex with the Rbp-J DNA-binding protein, which is the primary mediator of Notch signaling, and the Mastermind coactivator; converts Rbp-J from a transcriptional repressor to a transcriptional activator; and induces transcription of target genes such as members of the Hairy enhancer of split (Hes) family of basic helixloop-helix (bHLH) DNA-binding transcription factors Hes1 or Hes5 and the Hes-related protein (Herp) family (for review, see Iso et al. 2003). In the Drosophila nervous system, Notch regulates a process of lateral inhibition, whereby a single neuron differentiates within a field of similar precursor cells. During lateral inhibition, cells expressing high levels of Notch ligand commit to neural differentiation and activate Notch signaling in their neighbors, thereby preventing them from adopting the same fate. Though Notch is best known for its role in 
lateral inhibition, activation of this pathway also promotes cell fate (Irvine 1999; Gaiano et al. 2000; Grandbarbe et al. 2003). Recent studies have shown that Notch signaling regulates a broad range of patterning processes during embryonic and postnatal development (Hitoshi et al. 2002; Krebs et al. 2003, Raya et al. 2003; Burns et al. 2005; Crosnier et al. 2005; Duncan et al. 2005; Fre et al. 2005; van Es et al. 2005; for reviews, see Lai 2004; Yoon and Gaiano 2005).

Coordination of signals from different pathways is essential for cell fate specification during animal development. The pituitary gland provides an excellent model system to study signaling events in organogenesis. The mature pituitary gland contains six hormone-producing cell types, including corticotropes secreting adrenocorticotrophic hormone (ACTH), a proteolytic product of proopiomelanocortin (POMC), thyrothopes secreting thyroid-stimulating hormone ( $\mathrm{TSH})$, somatotropes secreting growth hormone $(\mathrm{GH})$, lactotropes secreting prolactin (PRL), gonadtropes secreting luteinizing hormone (LH) and follicle-stimulating hormone (FSH), and melanotropes secreting melanocyte-stimulating hormone (MSH), a cleaved product of POMC. These cells derive from a common primordium, Rathke's pouch, and appear in a defined temporal and spatial fashion (Japon et al. 1994; for reviews, see Watkins-Chow and Camper 1998; Sheng and Westphal 1999; Dasen and Rosenfeld 2001; Rizzoti and Lovell-Badge 2005). Three of these cell types-thyrothopes, somatotropes, and lactotropes-differentiate from Pit1-expressing precursors and depend on the function of Pit1, a tissue-specific POU-class homeodomain transcription factor (Camper et al. 1990; Li et al. 1990). The expression of Pit1 is positively regulated by the concerted efforts of the paired-like homeodomain transcription factor, Prophet of Pit1 (Prop1), and the Wnt/ $\beta$-catenin signaling pathway (Gage et al. 1996; Sornson et al. 1996; Olson et al. 2006). Mutations in Pit1 or Prop 1 result in a failure of Pit 1 lineages differentiation, leading to a postnatal dwarf phenotype (Camper et al. 1990; Li et al. 1990; Ward et al. 2005). Differentiation of corticotropes is dependent on the T-box transcription factor, Tbx19, and regulated by other transcription factors and signaling events (Lamolet et al. 2001; Liu et al. 2001; Chesnokova and Melmed 2002; Pulichino et al. 2003).

Multiple signaling pathways converge to dictate molecular events underlying pituitary development. Lossof-function and gain-of-function genetic studies together with ex vivo organ culture experiments have identified essential roles of FGF signaling emanating from the ventral diencephalon in proliferation and survival of progenitor cells comprising Rathke's pouch, as well as in establishing a dorsal to ventral gradient within the nascent pituitary gland (Ericson et al. 1998; Treier et al. 1998; Ohuchi et al. 2000; Revest et al. 2001). In addition, whereas BMP4 signaling is required for the pituitary organ commitment, BMP2 establishes a ventral to dorsal gradient necessary for cell type determination (Ericson et al. 1998; Takuma et al. 1998; Treier et al. 1998). Moreover, $\mathrm{SHH}$ signaling also exerts critical roles in support- ing proliferation and terminal differentiation (Treier et al. 2001; Herzog et al. 2003; Sbrogna et al. 2003). Here, we report that the evolutionarily conserved Notch signaling pathway functions in the early phases of pituitary organogenesis to prevent premature differentiation of progenitors and drive specification of Pit1 precursors, which would otherwise emerge as the POMC-expressing corticotropes. Attenuation of Notch signaling at a later phase of pituitary development is required for the proper cell type terminal differentiation. These findings establish an additional role of the Notch signaling pathway in controlling the emergence of distinct precursor subtypes.

\section{Results}

Core components of the Notch signaling pathway during pituitary development

To explore the potential function of the Notch signaling pathway during pituitary development, in situ hybridization was carried out to examine the expression pattern of the known mammalian Notch ligands and receptors, D111, D113, D114, Jag1, Jag2, and Notch1-Notch4, respectively, as well as the direct downstream targets of Notch signaling, Hes1, Hes5, and Hey1. Jag1, Dll1, Notch2, and Notch3, as well as Hes1 and Hey1, were expressed in the Rathke's pouch, indicating that Notch signaling is active during early pituitary development (Figs. 1, 2). At embryonic day 9.5 (E9.5), Jag1, Notch2, Notch3, and Hes1 are expressed in the invaginating oral ectoderm. Between E10.5 and E12.5, Jag1, D111, Notch2, and Notch 3 are detected throughout Rathke's pouch, with Hes1 demonstrating a restriction from the ventralmost region by E12.5. By the onset of Pit1 expression at E13.5, D111, Notch2, Notch3, and Hes1 expression have begun to be down-regulated in the perspective anterior pituitary, while persisting in the perilumenal cells. By contrast, Jag1 expression appears largely restricted to mesenchymal cells lining the invaginated Rathke's pouch. At later stages of pituitary development for E14.5 and E17.5, D111, Notch2, Notch3, and Hes1 were detectable only in cells adjacent to the lumen. These expression patterns reveal that both the ligands and receptors of the Notch pathway are expressed in early stages of pituitary development, and that subsequent down-regulation of expression correlates well with the onset of the pituitary gland maturation, consistent with an inhibitory role for Notch signaling in regulating cell terminal differentiation in the developing pituitary. While D113 is not expressed in early stages of Rathke's pouch formation, its expression is detectable at E14.5 and E17.5 in the intermediate lobe as reported previously (Supplementary Fig. 1), although no defect in melanotrope differentiation was observed in D113 ${ }^{-/-}$embryos (Raetzman et al. 2004).

Notch activity-dependent Hes 1 expression controls the timing of corticotropes differentiation

The expression of multiple Notch receptors and ligands during early stages of pituitary development suggested 


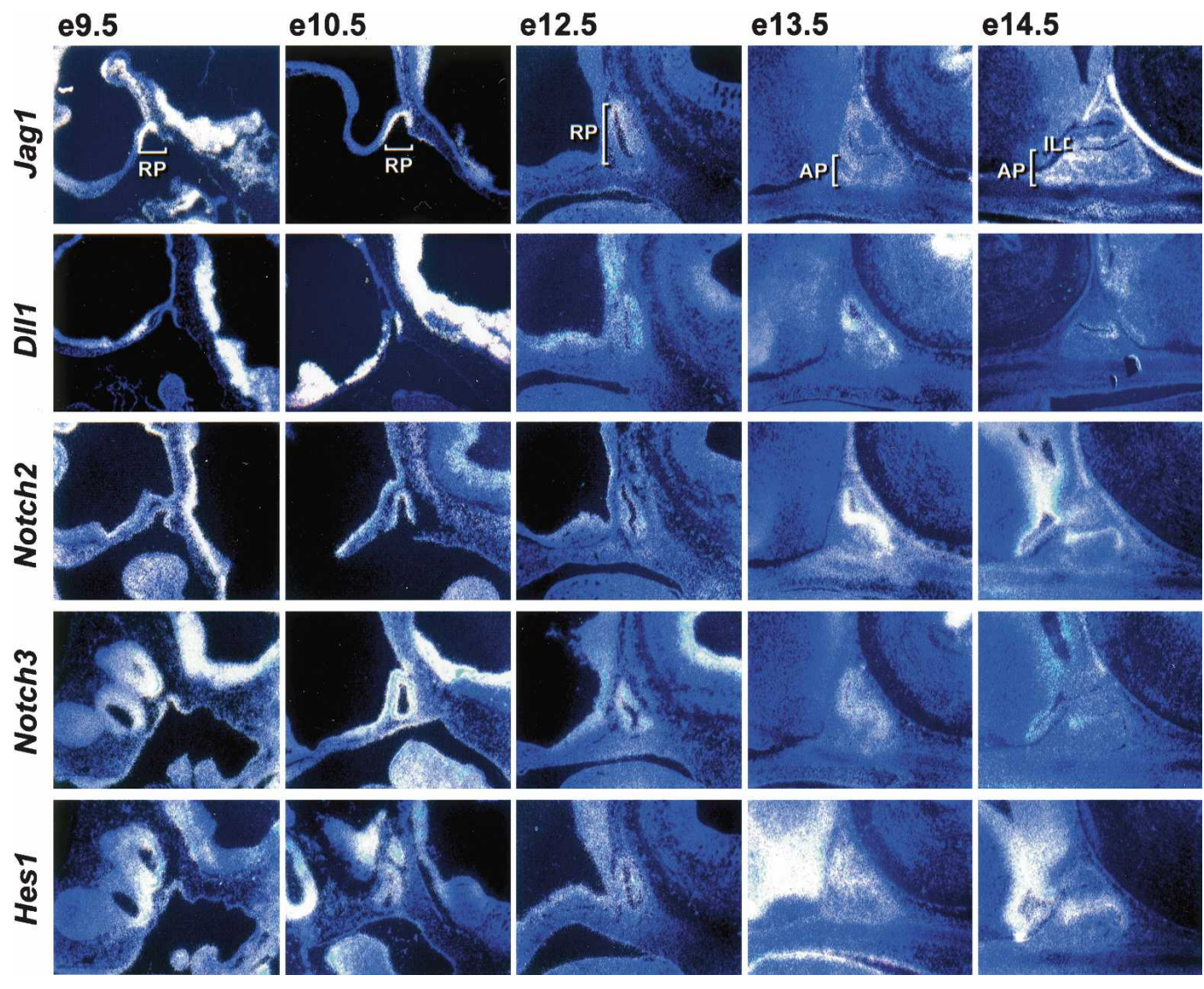

Figure 1. In situ analysis of expression pattern of core components of the Notch signaling pathway during pituitary development. Two ligands (Dl11, Jag1), two receptors (Notch2, Notch3), and the downstream target of Notch/Rbp-J signaling (Hes1) are expressed in the oral ectoderm and the Rathke's pouch (RP) by E12.5. At E13.5, Dll1, Jag1, Notch2, Notch3, and Hes1 expression are down-regulated in the anterior pituitary (AP) and are further confined to the perilumenal cells. At E14.5, Jag1 is expressed in the mesenchymal cells surrounding and within the pituitary gland. (IL) Intermediate lobe.

that analysis of the endogenous functions of Notch signaling would be most effective through manipulating the expression of the DNA-binding protein Rbp-J, the primary mediator of Notch signaling. We therefore deleted the Rbp-I gene in Rathke's pouch by crossing mice containing a floxed $R b p-J$ allele (Tanigaki et al. 2002) with transgenic mice expressing the Cre recombinase under control of the Pitx1 promoter (Pitx1-Cre). This Cre allele exhibited efficient Cre-recombinase activity starting at E9.0 in all progenitors of Rathke's pouch (Olson et al. 2006). Quantitative RT-PCR of mRNA from microdissected E12.5 pituitaries revealed that floxed $R p b-J$ exons 6 and 7 were down-regulated fourfold in $R b p-f^{\mathrm{f} / \mathrm{f}}$, Pitx1-Cre embryos in comparison with $R b p-f^{f /+}$, Pitx1Cre mice (data not shown). In situ hybridization readily detected a decrease in Hes1 and Hey1 expression at E11.5, suggesting that Pitx1-Cre can effectively mediate floxed $R b p-I$ recombination in pituitary premordium, and Hes1 and Hey 1 are downstream targets of the Notch signaling in the pituitary (Fig. 2). Because Hes1 is required in multiple tissues for proper development, we also probed the function of Hes1 in pituitary organogenesis in order to compare the effects of loss of Notch activity and the loss of a downstream target of Notch sig- naling. Interestingly, Rbp- $f^{f / f}$, Pitx1-Cre embryos isolated at E12.5 exhibited similar phenotypes to those observed in $\mathrm{Hes}^{-/-}$embryos (Fig. 2). In situ hybridization and immunofluorescence staining revealed premature differentiation of corticotropes at the most ventral region of the pouch, with concomitant up-regulation of Tbx19/Tpit, the function of which is necessary for corticotrope terminal differentiation (Pulichino et al. 2003). Expression of bHLH factors such as Mash1, NeuroD1, and Math3 were also expanded or ectopically up-regulated, except that no apparent up-regulation of Math3 was observed in $\mathrm{Hes}^{-/-}$. Interestingly, activation of these bHLH factors was restrained in the ventral-most region of the pouch where differentiated corticotropes were observed, suggesting that ablation of Notch activity, or relief from Hes1 repression, is insufficient to activate their expression and that additional components are required.

In the absence of either Notch activity or Hes1, there is a decreased number of proliferating pituitary progenitors and an increased number of cells exiting the cell cycle, as demonstrated by the proliferation marker Ki67 staining and bromodeoxyuridine (BrdU) labeling (Fig. 2; Supplementary Fig. 2). The cells in the vicinity of the 
Zhu et al.
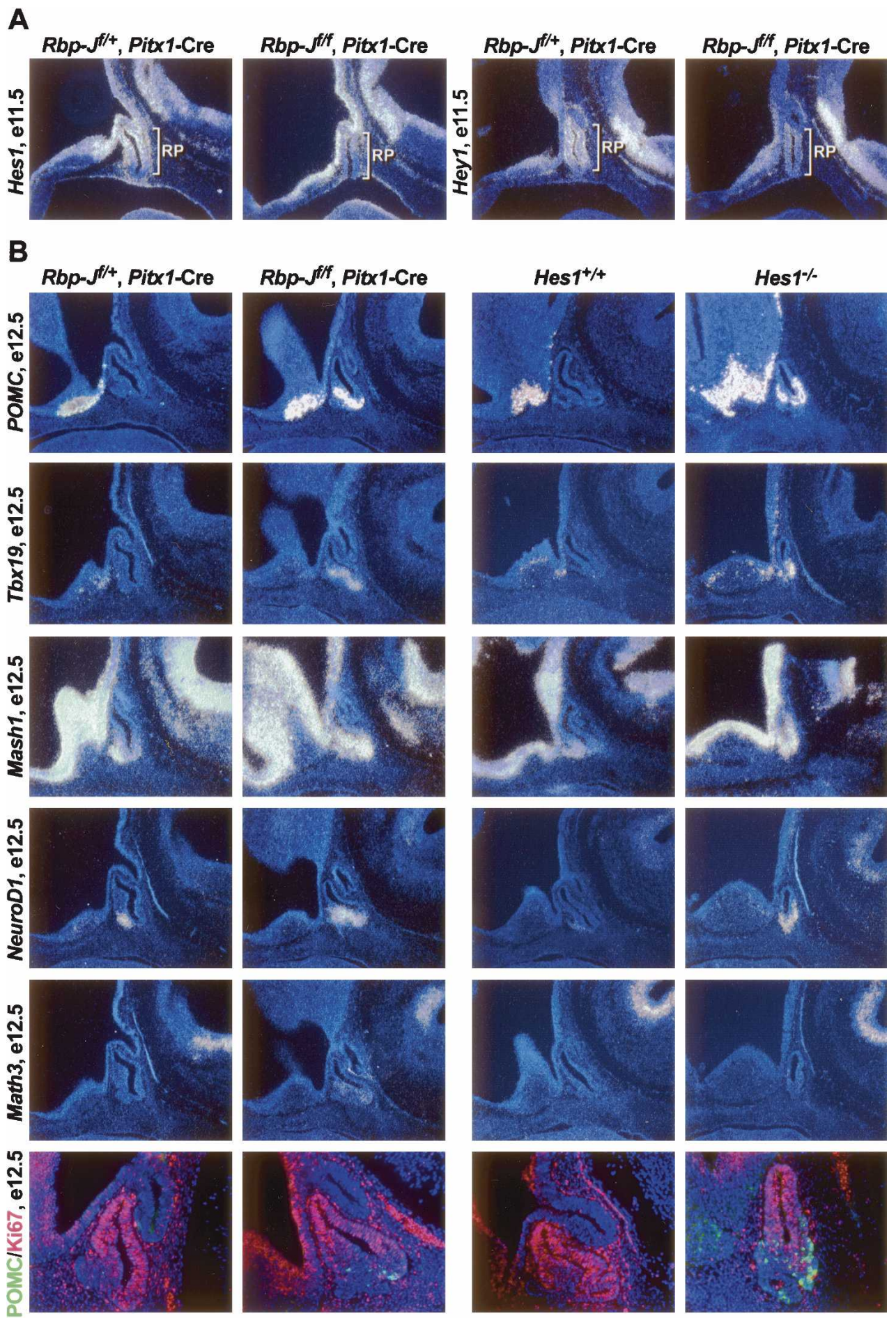

Figure 2. Notch signaling represses premature corticotrope differentiation via its downstream target Hes1. (A) Hes1 and Hey1 are down-regulated in $R b p-f^{\mathrm{f} / \mathrm{f}}$, Pitx1-Cre mice at E11.5. (B) Premature corticotrope differentiation is indicated by POMC as well as Tbx19 expression in Rbp- $f^{\mathrm{f} / \mathrm{f}}$, Pitx1-Cre mice at E12.5. Expression of bHLH genes, including Mash1, NeuroD1, and Math3, are up-regulated but restricted in the ventral region of Rathke's pouch. Corticotrope premature differentiation is evident in Hes $1^{-/-}$mice, accompanied by up-regulation of Tbx19, Mash1, and NeuroD1. However, there is no pronounced ectopic expression of Math3. The posterior lobe of pituitary of $\mathrm{Hes}^{-/-}$mice is absent. Double-immunofluorescence staining of POMC and Ki67 in E12.5 embryos showed increased

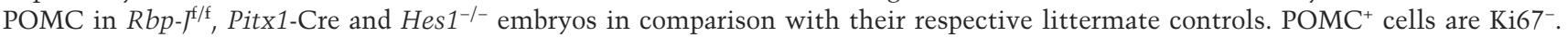
Cells surrounding the lumen remain proliferative, while more cells at the ventral region of the pouch in mutant embryos exit the cell cycle and are negative for Ki67 staining. 
lumen remained proliferative, whereas a higher proportion of cells in the caudomedial region ceased proliferation as compared with control littermates. These differences are not due to enhanced cell death as no significant differences in apoptosis were observed in both the $R b p$ $f^{\mathrm{f} / \mathrm{f}} /$ Pitx1-Cre and the Hes1 ${ }^{-/-}$mice, demonstrated by staining for cleaved caspase-3 (data not shown). Double staining of Ki67 and POMC demonstrated that differentiated $\mathrm{POMC}^{+}$corticotropes are Ki67-' therefore excluding the possibility that the increased number of corticotropes is a consequence of increased proliferation.

Taken together, these data demonstrate that Notch activation is required to prevent premature differentiation of corticotropes, and that Hes1 is a primary target mediating the Notch pathway in the control of the timing of corticotrope differentiation. In addition, the presence of proliferating progenitors in the absence of Notch activity demonstrates that Notch signaling is not the sole determinant in maintaining the progenitor cell status during pituitary development.

Notch signaling is required for the commitment of Pit $1^{+}$precursor cell fate by regulating

Prop1 expression

During pituitary development, the next cell lineage commitment following the initial determination of corticotropes is characterized by the appearance of Pit1 transcripts at E13.5. In the Rbp-f/f/f Pitx1-Cre mice, Pit1 expression fails to be initiated (Fig. 3A), and at E17.5, when the lateral region of the anterior pituitary would be normally populated with Pit $1^{+}$cells, most of which would be $\mathrm{GH}^{+}$somatotropes, only a few $\mathrm{Pit}^{+}{ }^{+}$cells could be identified in the $R b p-f^{t / f}$, Pitx1-Cre mice by either in situ hybridization or immunofluorescence labeling. Consequently, only a few $\mathrm{GH}^{+}$somatotropes, and almost no TSH $\beta^{+}$thyrotropes, could be detected (Fig. 3A). Instead, at E14.5 and E17.5, the anterior pituitary was composed predominately of $\mathrm{POMC}^{+}$corticotropes (Fig. 3C; Supplementary Fig. 3). Gonadotrope differentiation, which occurs independently of Pit1 expression, was not significantly affected, as judged by expression of SF1 and $L H \beta$ (Fig. 3A). These results demonstrate that Notch signaling is necessary to induce the onset of Pit1 lineage commitment, and, in its absence, the progenitors take on a corticotrope fate at the expense of the Pitl lineage. By contrast, analysis of the Hes $1^{-1-}$ mice revealed that the ontogeny of initial Pit1 induction, terminal differentiation of Pit1 lineages, occurred normally (Fig. 3B; Supplementary Fig. 4). These data suggest that down-regulation of Hes1 does not account for the defects in Pit1 induction observed in $R b p-I$ mutant embryos, and that Notch signaling may control $\mathrm{Pit}^{+}$lineage commitment by regulating downstream targets other than Hes1.

Because Pit1 activation is regulated by the concerted actions of Prop 1 and the Wnt/ $\beta$-catenin signaling pathway, we sought to examine the expression of Prop1 as well as Axin2, a direct downstream target of $\mathrm{Wnt} / \beta$ catenin signaling and therefore serving as an indicator of signaling activity in this pathway (Olson et al. 2006). In situ hybridization analyses revealed no significant differences in Axin2 expression in the Rbp- $f^{\mathrm{f} / \mathrm{f}}$, Pitx1-Cre mice as compared with heterozygous littermates, implying that the Wnt $/ \beta$-catenin signaling remained intact in the absence of Notch activity (Fig. 4B). Prop1 expression, conversely, was markedly diminished by E12.5, when levels of Prop1 mRNA normally peak. We further noted that at E11.5, when Prop1 is initially expressed at lower levels, there was no obvious difference in the Prop1 expression profile exhibited by the mutant and the control (Fig. 4A), suggesting that Notch activity is required for the up-regulation of Prop1 at E12.5, but not the initiation of Prop1 expression. By comparison, Prop1 transcripts in Hes $1^{-/-}$mice at E12.5 were not significantly affected (Fig. 4B), consistent with the model that Rbp-J may modulate Prop1 expression directly.

To further investigate the molecular mechanism underlying the genetic relationship between Notch activity and Prop 1 expression, an in silico search utilizing VISTA (http://rvista.dcode.org) was performed for conserved noncoding regions in the Prop1 genes among six mammalian species: mouse, rat, dog, sheep, bovine, and human. Two highly evolutionarily conserved regions $(>75 \%)$ were identified, in the promoter and the first intron, respectively. A search for conserved regulatory elements in these regions identified a consensus binding site for Rbp-J within the first intron (Fig. 4C). In order to examine whether this putative binding site might be recognized by Rbp-J, we performed electrophoretic mobility shift assays (EMSA) using synthetic oligonucleotides representing the putative binding site and flanking regions, and Rbp-J produced by in vitro transcription and translation. Rbp-J bound efficiently to the Prop1 intron in vitro, and this binding could be competed with itself or a known Rbp-J-binding site, but not with oligonucleotides in which the putative recognition sites had been mutated (Fig. 4D).

In order to estimate whether Rbp-J is recruited to the Prop1 gene in vivo, we performed chromatin immunoprecipitation (ChIP) analysis from E12.5 dissected pituitaries using antiserum specific for Rbp-J (Chu and Bresnick 2004). The results revealed recruitment of Rbp-J to the promoter of Hes1, as well as to the first intron of Prop1, suggesting that Prop1 is a direct target of Notch signaling activity in the pituitary (Fig. 4E). Consistent with these in vivo findings, transient cotransfection reporter assays in the pituitary cell line GHFT1 employing either a $2-\mathrm{kb}$ fragment including the promoter and first intron of Prop1, or the evolutionarily conserved intron region in conjunction with a heterologous minimal promoter, demonstrate that reporter activity was inhibited by small interfering RNA (siRNA) directed against Rbp-J (Fig. 4F,G). These data support a mechanistic role of Rbp-j in direct regulation of Prop1.

\section{Notch activity is necessary to suppress melanotrope} cell fate

While the ventromedial regions of Rathke's pouch differentiate into Pit $^{+}$precursors, cells originating from 
A
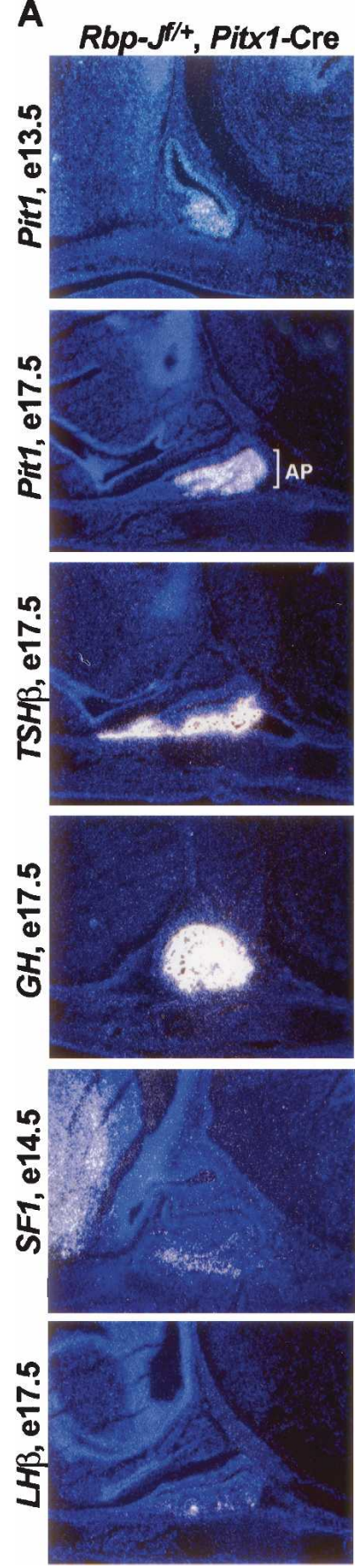
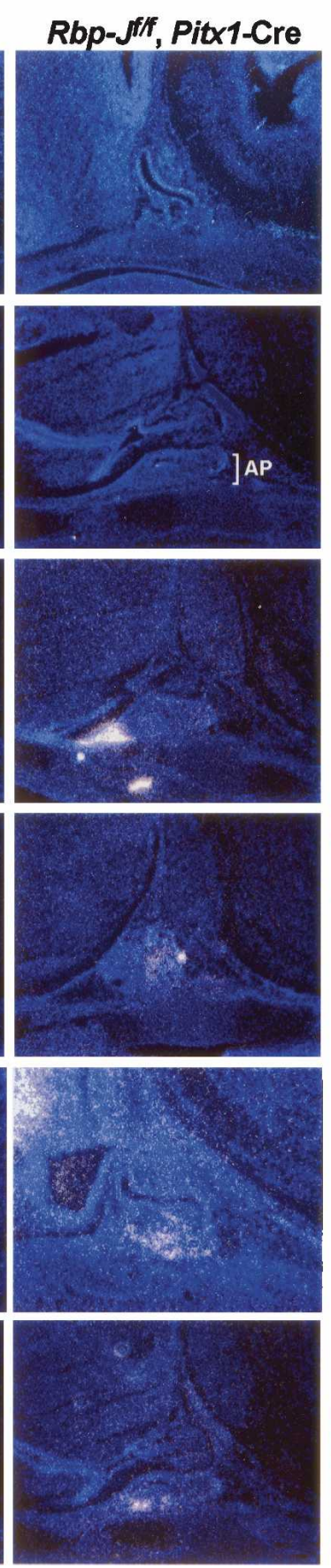

B
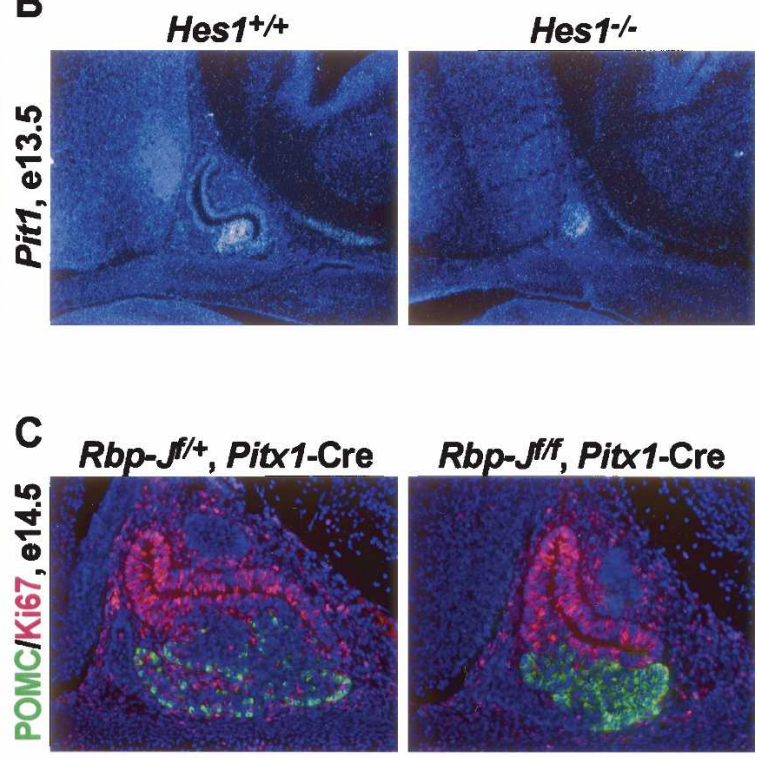

Rbp-Jff, Pitx1-Cre
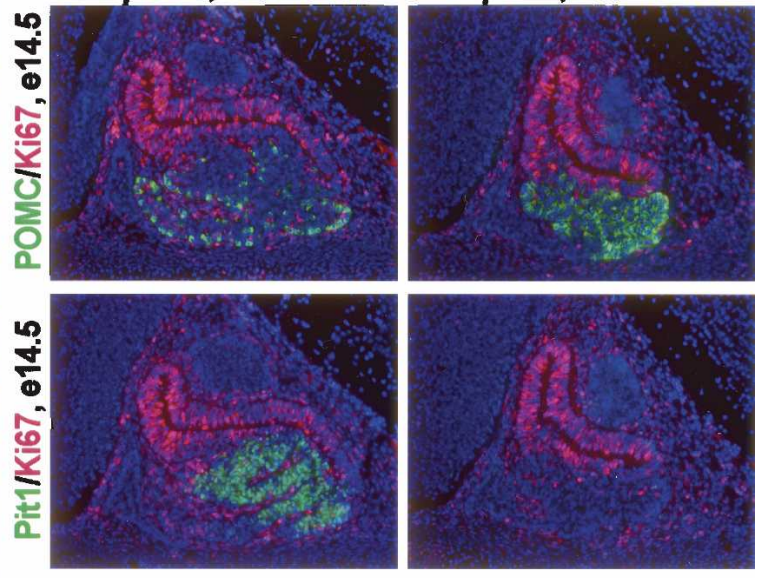

D Rbp-Jf/+, Pitx1-Cre
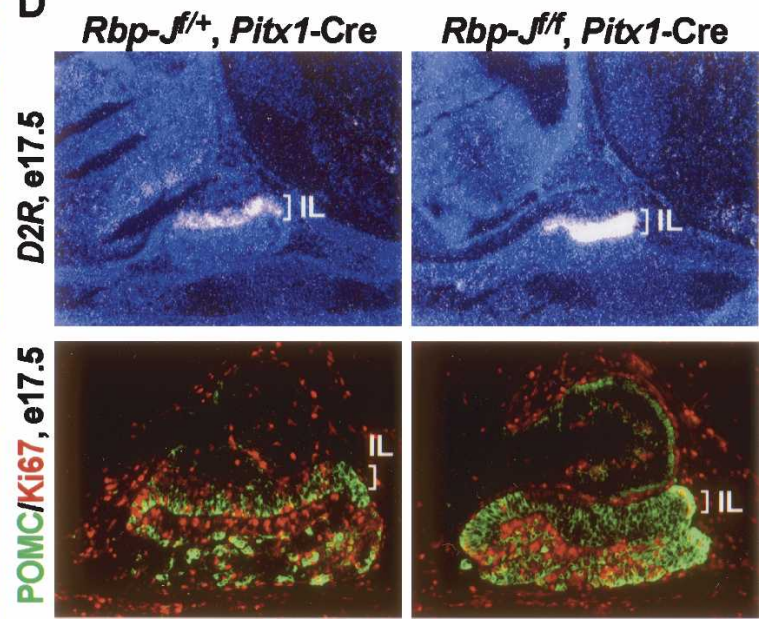

Figure 3. Notch signaling is required for Pit1 lineage commitment. (A) Pit1 expression is absent in Rbp- $f^{\mathrm{f} / \mathrm{f}}$, Pitx1-Cre mutant embryos at E13.5. At E17.5, Rbp- $f^{\mathrm{f} / \mathrm{f}}$, Pitx1-Cre mutant embryos, Pit1 expression, and differentiation of Pit1 lineages thyrotropes $(T S H \beta)$ and somatotropes $(G H)$ are impaired, while gonadotrope commitment, indicated by SF1 expression at E14.5 and $L H$ expression at E17.5, is not affected in Rbp- $f^{\mathrm{f} / \mathrm{f}}$, Pitx1-Cre mutant embryos. (B) Pit1 induction occurs normally in E13.5 Hes $1^{-/-}$embryos. $(C)$ Double-immunofluorescence staining of POMC (green) and Ki67 (red), or Pit1 (green) and Ki67 (red) at E14.5 pituitaries shows that the anterior pituitary of the $R b p-f^{\mathrm{f} / \mathrm{f}}$, Pitx1-Cre mutant is populated with an increased number of corticotropes and is devoid of Pit $1^{+}$cells. The differentiated cells are not proliferative, as indicated by Ki67 staining. Cells surrounding the lumen are Ki67 in both $R b p-f^{f / f}$, Pitx-Cre mutant embryos and littermate controls. $(D) D 2 R$ expression at the intermediate lobe (IL) is increased in Rbp- $f^{\mathrm{f} / \mathrm{f}}$, Pitx 1 -Cre mutant embryos at E17.5. Dual-immunofluorescence labeling of POMC (green) and Ki67 (red) at E17.5 pituitaries shows almost all $\mathrm{POMC}^{+}$cells in IL are $\mathrm{Ki}^{-} 7^{-}$.

the dorsal regions of the pouch continue to proliferate, eventually differentiating into $\mathrm{Tbx} 19^{+}, \mathrm{Mash}^{+}, \mathrm{D} 2 \mathrm{R}^{+}$ (dopamine D2 receptor), $\mathrm{POMC}^{+}$intermediate lobe melanotropes (Meador-Woodruff et al. 1989; Japon et al. 
A
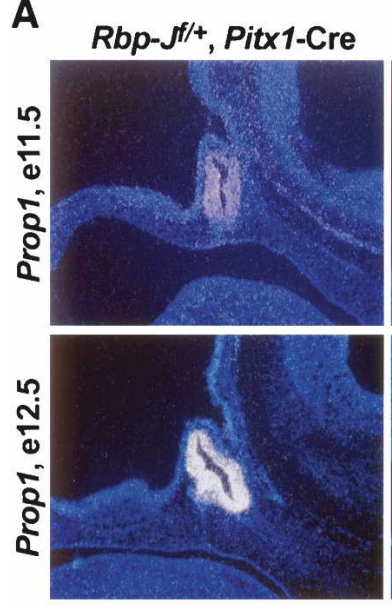

B

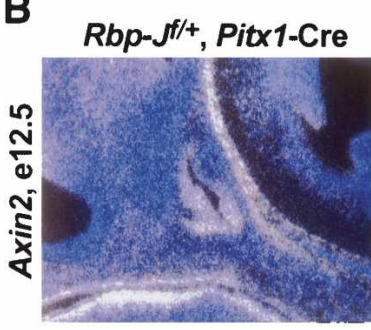

Hes $1^{+/+}$

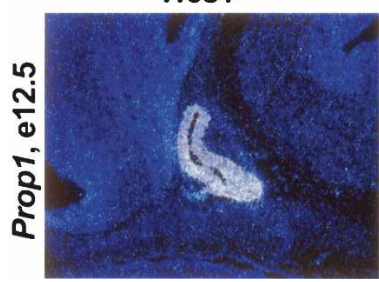

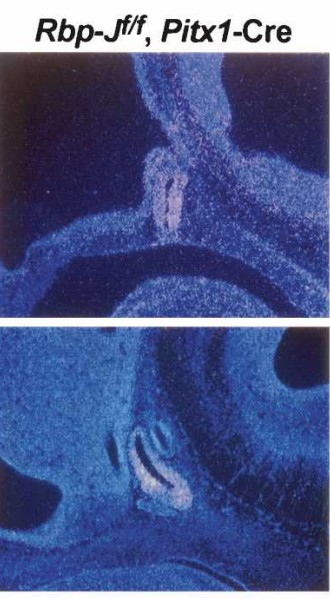

Rbp-Jff, Pitx1-Cre

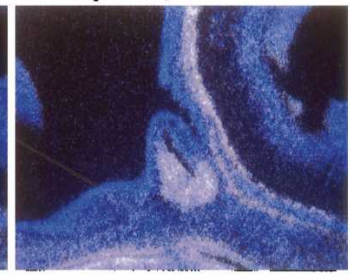

Hes 1-1-

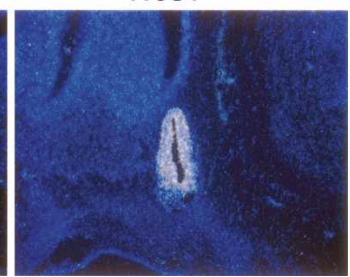

C

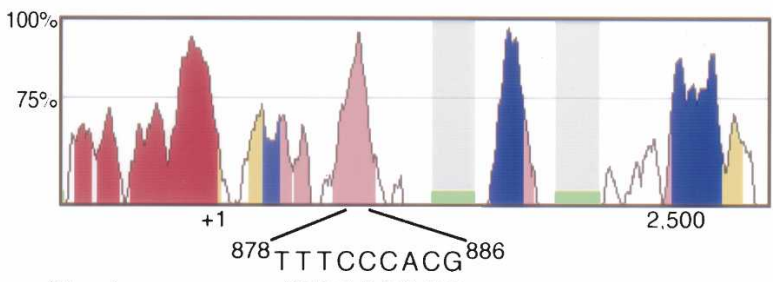

Rbp-J consensus g/tT TCCCACG
EMSA

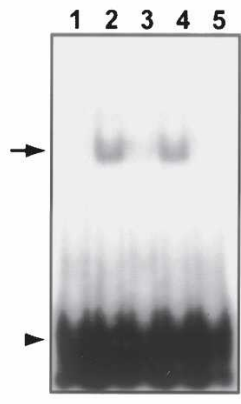

$\mathbf{F}$

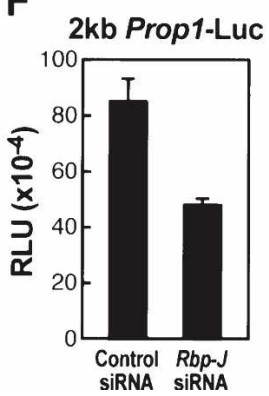

E

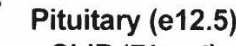

ChIP (Rbp-J)

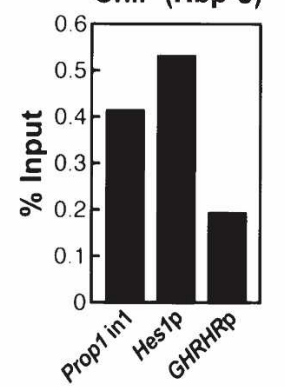

G

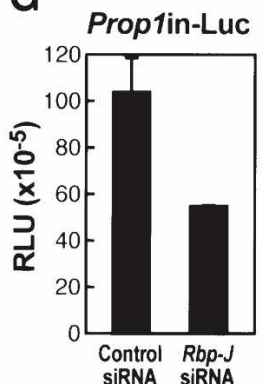

Figure 4. Prop 1 is a direct target of Notch signaling. (A) Prop 1 expression is significantly down-regulated in $R b p$ - $-^{\mathrm{f} / \mathrm{f}}$, Pitx 1 -Cre mutant embryos at E12.5 but is unchanged at E11.5. (B) Axin2 expression in Rbp-f/f, Pitx1-Cre mutant embryos and Prop1 expression in Hes $1^{-/-}$at E12.5 are not significantly changed. (C) Genomic DNA sequences of mouse and human Prop1 were compared using VISTA. (Red) Promoters, (yellow) UTRs, (blue) exons, (pink) introns. Two evolutionarily conserved regions, the promoter and the first intron, show $>75 \%$ homology. A putative Rbp-J-binding site is identified in the first intron. $(D)$ A ${ }^{32} \mathrm{P}$-labeled 25 -bp oligonucleotide encompassing the putative Rbp-J-binding site was incubated in the absence (lane 1) or in the presence (lanes 2-5) of in vitro translated Rbp-J and the competitors. Unlabeled oligonucleotides (lane 3), equivalent oligonucleotides where the putative Rbp-J-binding site was mutated (lane 4), or the oligonucleotides containing a Rbp-J-binding site from Epstein-Barr virus C promoter region (lane 5) were used as competitors at 100× molar excess. The arrow indicates the shifted probe caused by Rbp-J binding, and the arrowhead indicates free probe. (E) Quantitative ChIP assay of E12.5 pituitaries using anti-Rbp-J showed recruitment of Rbp-J to the first intron of Prop1. The promoter regions of the Hes1 and GHRHR were used as the positive and negative controls, respectively. $(F, G)$ Transient transfection of 2-kb Prop1-Luc $(F)$ or Prop1in-Luc $(G)$ with control siRNA or siRNA specific to Rbp-J.

1994; Lamolet et al. 2001; Liu et al. 2001; Pulichino et al. 2003). In situ hybridization analyses of $D 2 R$, and immunostaining of POMC at E17.5, revealed an increase in the overall number of melanotropes in the intermediate lobe of the $R b p-f^{f / f}$, Pitx1-Cre mice as compared with control littermates (Fig. 3D). Double-immunofluorescence staining of POMC and Ki67 revealed that intermediate lobe $\mathrm{POMC}^{+}$cells were negative for Ki67 staining, ruling out the possibility that expansion of the melanotrope population was caused by increased proliferation. By comparison, $\mathrm{Ki} 67^{+}$cells in the intermediate lobe were significantly diminished in Rbp- $f^{f / f}$, Pitx1-Cre mice, suggesting that more progenitors were differentiated to melano- trope cell fate in the absence of Notch activity. Intriguingly, the intermediate lobe of the Hes1-/- embryo is virtually absent (Supplementary Fig. 4). This is likely due to a nonpituitary effect and is currently under investigation.

\section{Ectopic Notch signaling prevents terminal cell differentiation}

Notch activity, as indicated by Hes1 expression, is down-regulated as cells undergo lineage commitment, suggesting that active Notch signaling may interfere with terminal differentiation. In order to test this hy- 
pothesis directly, we employed a transgenic mouse model engineered to sustain Notch signaling in Pit1-expressing cells by expressing epitope-tagged Notch1 ICD (NICD) under the control of a 15-kb 5' flanking region of the Pit1 promoter, which has been shown to activate target gene expression in three distinct Pit1-dependent lineages. Transgenic mice exhibit a postnatal dwarf phenotype, weighing one-half of wild-type littermates at 1 mo of age; they remain smaller than wild-type littermates throughout life. Analyses of adult transgenic and wild-type littermates revealed hypoplasia of the anterior pituitary in transgenic mice, with prominent reduction of somatotrope, thyrotrope, and lactotrope populations (data not shown). These observations demonstrate that sustained expression of activated Notch in Pit $1^{+}$precursors inhibited terminal differentiation of three Pit1-dependent lineages.

Examination of ectopic NICD expression by immunohistochemistry using an epitope-specific antibody demonstrated a spatial and temporal pattern of expression in the anterior pituitary almost identical to that of endogenous Pit1 expression, initiated at E13.5, and sustained thereafter (Fig. 5A). Dual immunofluorescence labeling with anti-Pitl and anti-HA revealed colocalization of Pit1 and NICD (Supplementary Fig. 3). Ectopic NICD expression in the Pit1 lineage did not affect apoptosis, as assessed by a TUNEL assay or cleaved caspase 3 immunostaining (data not shown), nor did it affect cell proliferation as assayed by BrdU labeling and Ki-67 staining at E17.5 (Fig. 5B; data not shown). In fact, at E13.5, when Pit1 is initially expressed, double-immunostaining analysis using anti-Pit1 and anti-Ki67 showed that almost all Pit1-expressing cell were Ki67-negative, suggesting that Pit $1^{+}$cells were not proliferating at this embryonic stage. Double-immunofluorescence labeling of Pit1 and Ki67 in E14.5 and E17.5 transgenic mice and wild-type controls showed that there was no significant difference in the number of $\mathrm{Pit}^{+} / \mathrm{Ki} 67^{+}$cells. Thus,

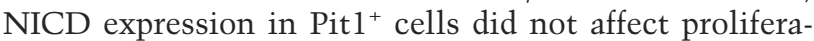
tion or survival of the Pit1 lineages (Fig. 5B). However, in situ hybridization analysis of E17.5 pituitaries from transgenic and wild-type littermates revealed a significant decrease of somatotropes and thyrotropes, as measured by GH, GHRHR (growth hormone-releasing hormone receptor), and TSH $\beta$ expression (Fig. 5C), with only occasional GH-positive cells and TSH $\beta$-positive cells observed at E17.5 pituitary in transgenic mice. To determine the origin of these cells, double-immunofluorescence labeling with antiserum specific for HA epitope and either $\mathrm{GH}$ or $\mathrm{TSH} \beta$ revealed that the residual $\mathrm{GH}^{+}$or $\mathrm{TSH}^{+}$cells in transgenic pituitaries were HA-negative, indicating they were derived from $\mathrm{Pit}^{+}$precursors that had failed to efficiently express the Pit1-NICD transgene (Fig. 5D). These results suggest that ectopic expression of NICD blocks terminal differentiation and that relief from the Notch repression is prerequisite for cells to undergo terminal differentiation. Pit1-independent corticotropes and gonadotrope lineages, expressing $P O M C$ and $L H \beta$, respectively, were not significantly affected by Pit1-NICD expression (Fig. 5C), suggesting that the ef- fects of Notch signaling on inhibition of terminal differentiation occurred in a cell-autonomous manner.

In Snell mice, which harbor a point mutation in the Pit1 gene that abolishes its transcriptional function, three Pit1 lineages are absent while gonadtropes are markedly increased (Dasen et al. 1999), and the latter phenotype was not observed in the NICD transgenic mice. Thus, our results implicated that NICD blocks lineage differentiation likely by interfering with pathways either parallel to or downstream from the Pit1 action.

\section{Ectopic NICD expression down-regulates proneural bHLH expression}

Because Hes1 and Hes5 are well established Notch targets in other tissues that in turn inhibit the expression or antagonize the functions of cells specifying bHLH proteins, we examined the expression of Hes 1 and Hes5, as well as Mash1 and NeuroD1, which are expressed during pituitary development (Liu et al. 2001; Lamolet et al. 2004). In situ hybridization analysis demonstrated upregulation of Hes1 and ectopic expression of Hes5 at E14.5 pituitaries of Pit1-NICD transgenic mice (Fig. 6A), whereas Hes1 expression is almost undetectable in the anterior pituitary of wild-type embryos at this stage of development and Hes5 is normally not expressed in pituitary (Figs. 1, 7A). These results indicate that the down-regulation of Hes1 expression in the wild-type anterior pituitary is most likely due to down-regulation of Notch receptors and ligands, and that Rbp-J itself apparently functions as a transcription repressor at later stages of pituitary development, consistent with the observation that overexpression of a dominant-negative form of Rbp-J (Rbp-J + engrailed repressor domain) in Pit $1^{+}$cells did not interfere with terminal differentiation of Pit1 lineages (X. Zhu, unpubl.).

As might be expected, sustained induction of Hes1 and Hes5 in Pit1-NICD transgenic mice results in significant down-regulation of Mash1 and NeuroD1 in the anterior pituitaries of transgenic mice (Fig. 6A). It has been reported recently that NeuroD1 is required for the early corticotrope differentiation but not lineage commitment (Lamolet et al. 2004), and in related studies, we have found that Mash1 exerts roles in terminal differentiation of thyrotropes, gonadtropes, and corticotropes (our unpublished data). Intrigued by these findings, we sought to explore if other proneural bHLH factors are expressed in the pituitary and, if so, whether they are also down-regulated by Pit1-NICD expression. A semiquantitative RTPCR comparing E14.5 wild-type and transgenic pituitaries was performed to characterize the potential expression of a panel of proneural bHLH factors and Math3 was identified, expression of which was markedly inhibited in transgenic embryos in comparison with wild-type littermates (Fig. 6A).

\section{Math3 is required for somatotrope maturation and function}

Targeted disruption of Math3 leads to cerebellar defects, with increased apoptosis in the external granular layer as 
A
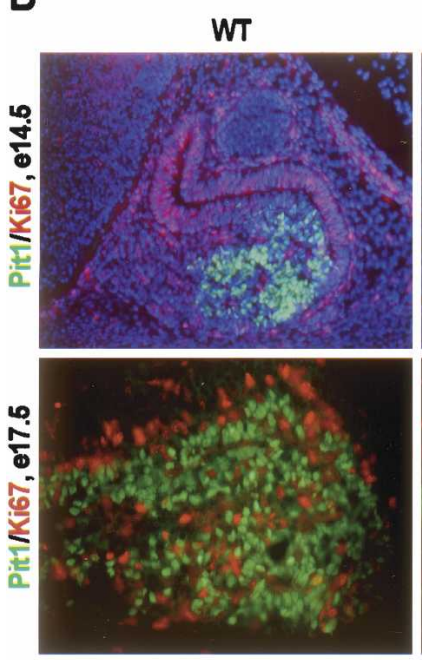

D

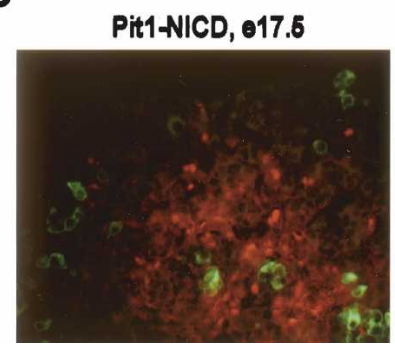

HA

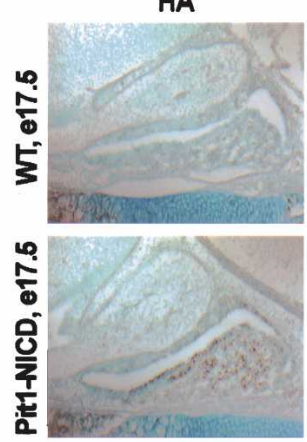

Pit1-NICD
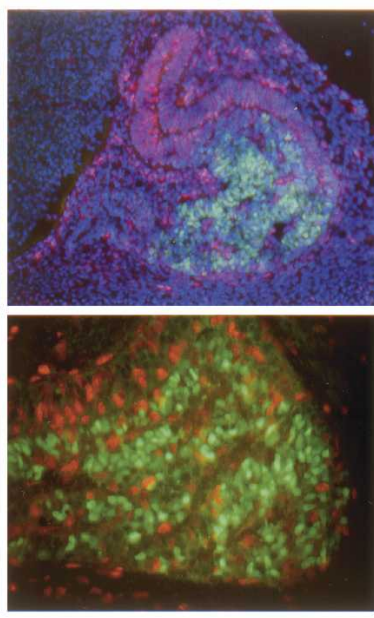

Pit1-NICD, Adult

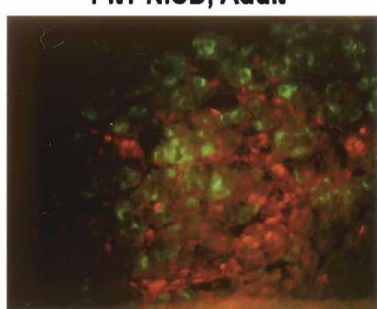

C
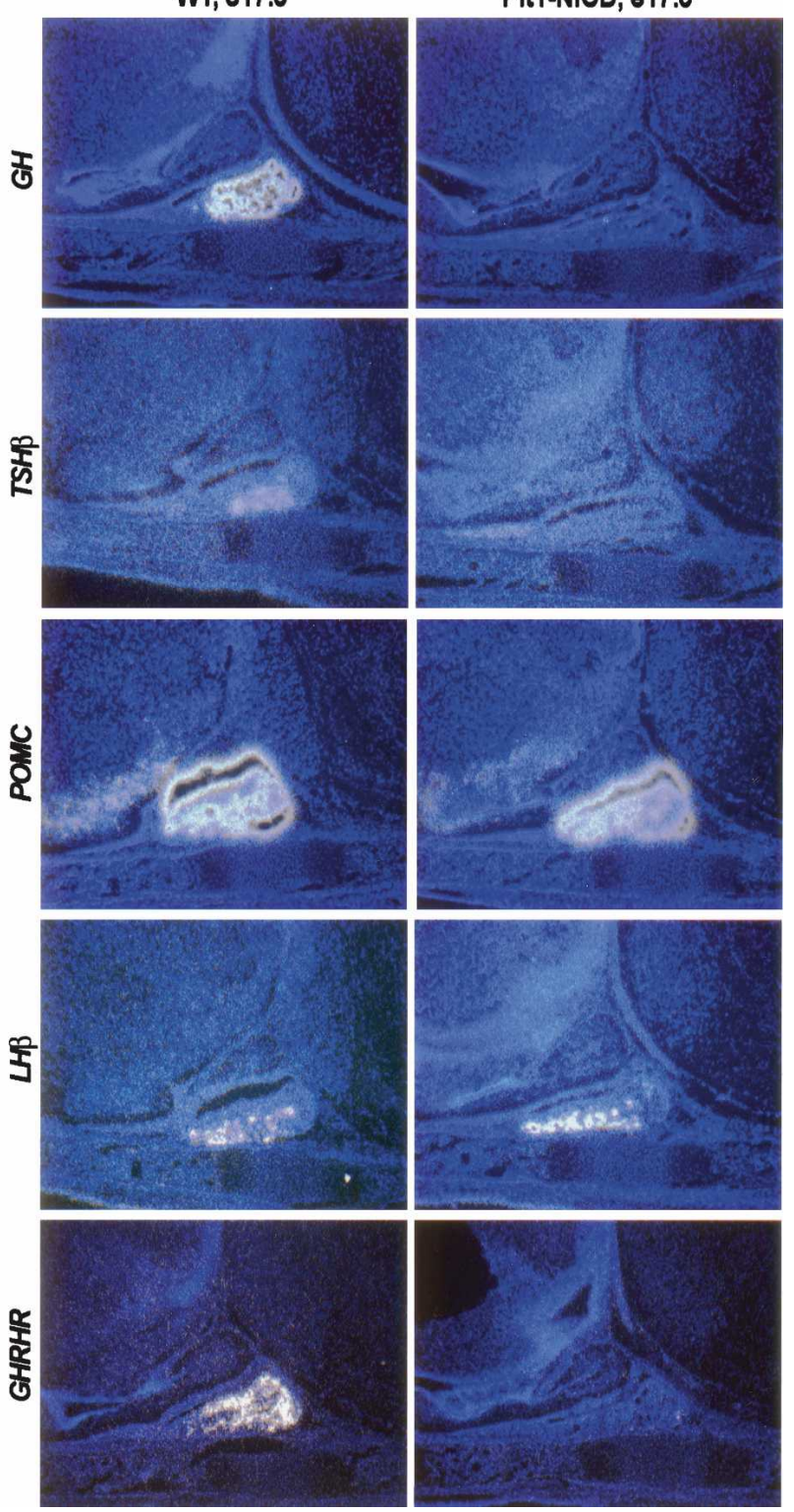

Pit1-NICD, 017.6
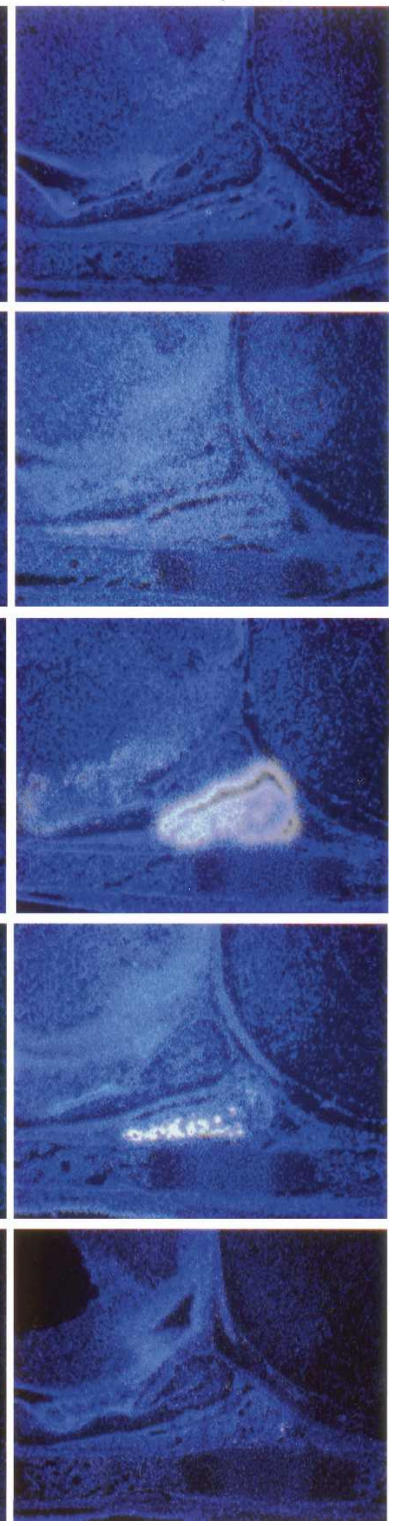

Figure 5. (A) Transient transfection in the pituitary GC cell line shows that the Pit1-NICD transgene construct can stimulate Hes1-Luc activity. Immunohistochemical staining with anti-HA antibody to detect transgene expression in E17.5 transgenic pituitary. Transgene expression is detectable as early as E13.5 when Pit1 expression begins. (B) Double-immunofluorescence staining of Pit1 (green) and Ki-67 (red) in wild-type and transgenic pituitary at E14.5 and E17.5 showed almost all proliferating cells are Pit1-negative at these stages and ectopic NICD expression in Pit1 lineage did not induce proliferation. $(C)$ Prolonged activation of Notch signaling inhibits terminal cell differentiation of Pit1 lineages. In situ analysis of the transgenic pituitaries was performed with the GH, TSH 3 , $P O M C, L H \beta$, and GHRHR. Differentiation of corticotropes and gonadotropes is less affected. $(D)$ Double-immunofluorescence staining of HA (red) and terminal differentiation markers GH (left, green) and TSH $\beta$ (right, green) in pituitaries of transgenic mice showed that differentiated cells did not express the transgene.

well as postnatal growth retardation (Tomita et al. 2000). However, the underlying molecular mechanism(s) regulated by Math3 during postnatal growth remains largely unknown. Because Math3 is expressed in the pituitary, and the postnatal dwarfism phenotype in $\mathrm{Math}^{-/-}$mice resembles those of the Pit1-NICD and Snell mice, we probed Math3 functions in pituitary development. In situ hybridization analysis revealed that Math3 expres- sion in the anterior pituitary begins at E13.5 and persists throughout adulthood (Fig. 6B). The spatio-temporal expression profile of Math3 is reminiscent of that of Pit1. In silico comparison of the promoter regions of Math3 from mouse and human using VISTA identified a consensus Pit1-binding site within a highly conserved region $(>75 \%)$ in the promoter (Fig. 6D), suggesting that Math3 is likely a direct downstream target of Pit1. ChIP 
A
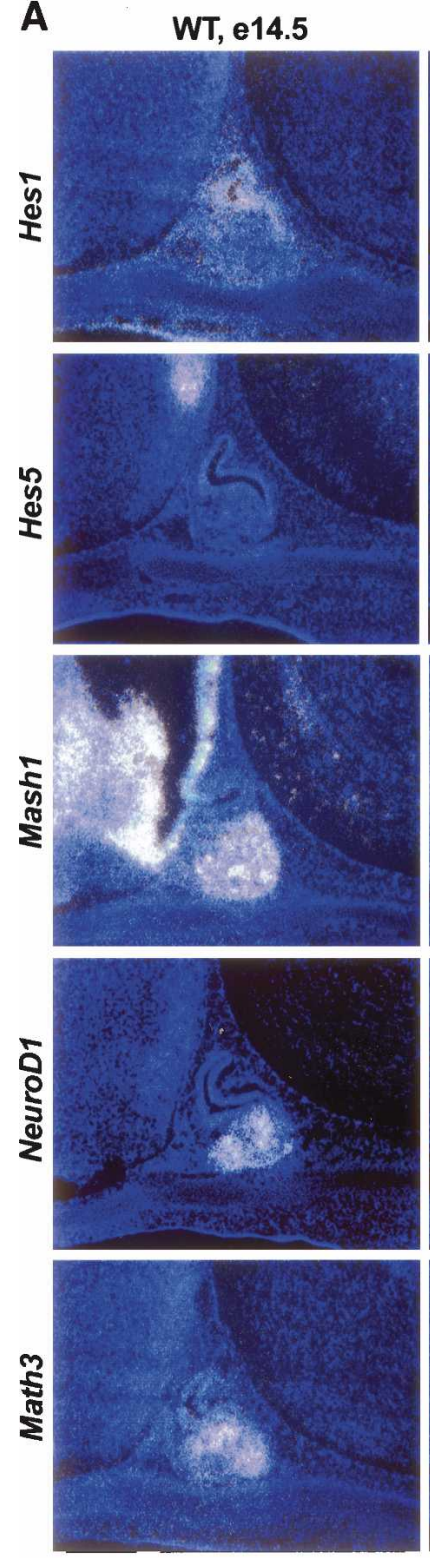

Pit1-NICD, e14.5
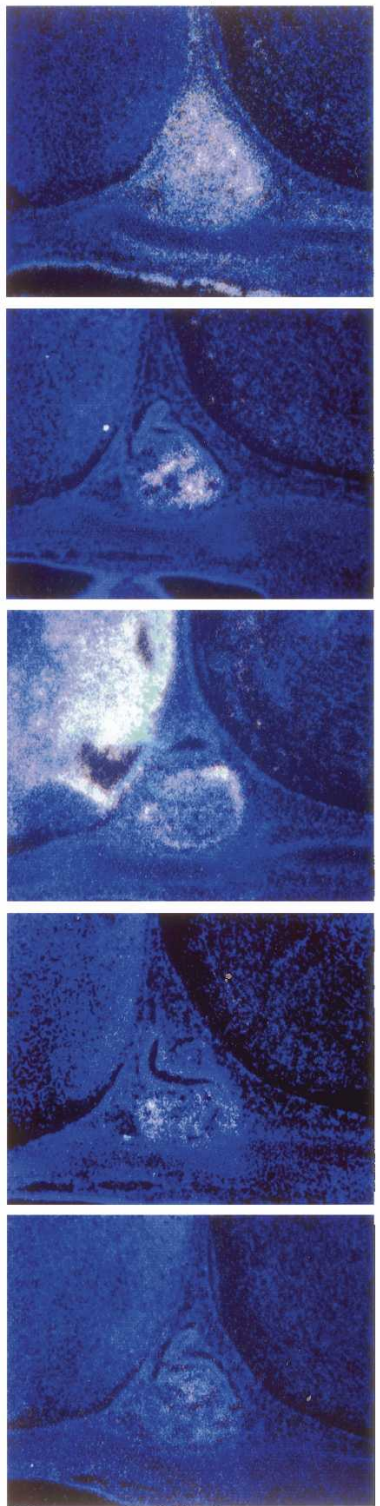

B
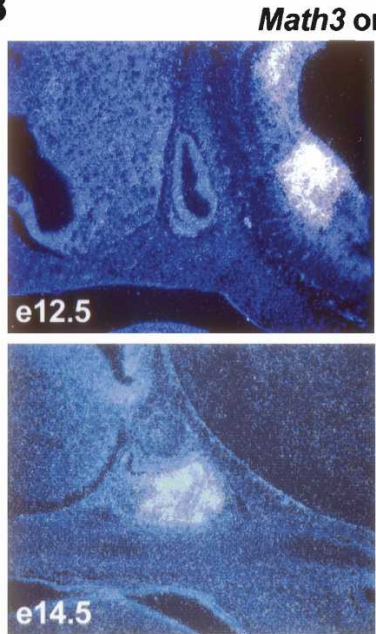

C
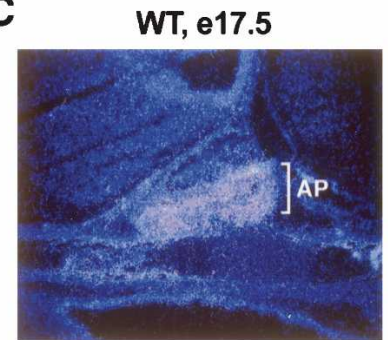

Snell, e17.5

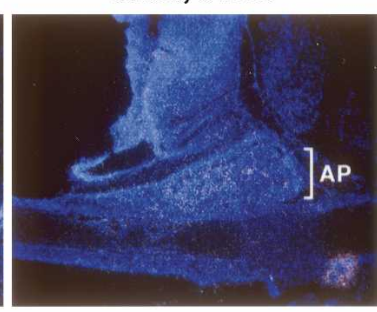

D
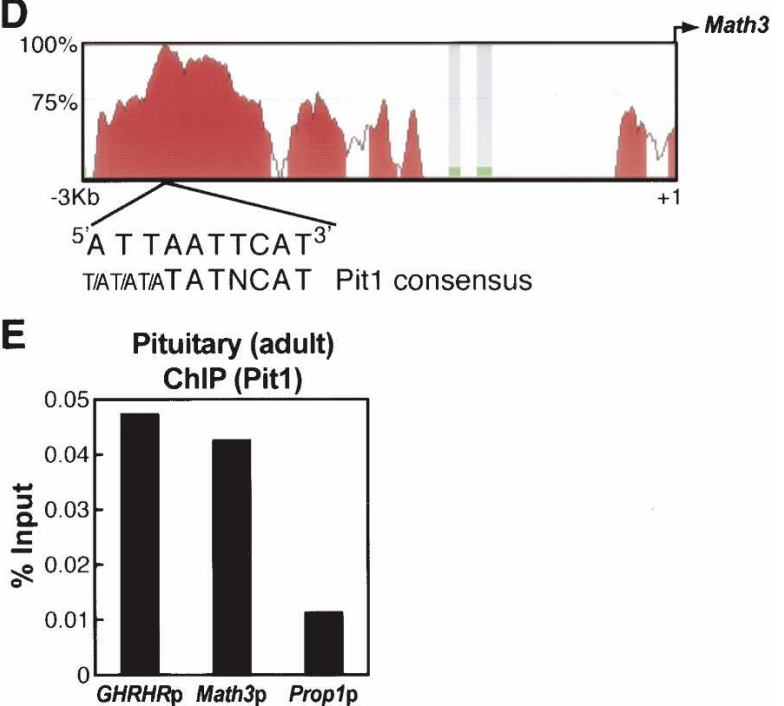

Figure 6. (A) In situ analysis of bHLHs expression in E14.5 pituitaries of transgenic mice and wild-type control. Both Hes1 and Hes5 were induced by ectopic NICD expression while Mash1, NeuroD1, and Math3 were significantly repressed. (B) Math3 expression ontogeny during pituitary development. Expression of Math3 begins at E13.5 in the caudomedial region of the anterior pituitary and persists in the anterior lobe of the adult pituitary. (C) Expression of Math3 is down-regulated in Snell mice at E17.5. (D) Alignment of the promoter regions of human and mouse Math3 using VISTA identified an evolutionarily conserved region in the promoter with $>75 \%$ homology. A putative binding site for Pit1 lies in this region. (E) ChIP from adult pituitaries using anti-Pit1 shows Pit1 is recruited to the Math3 as well as GHRHR promoter regions.

analysis of adult mouse pituitaries revealed recruitment of Pit1 to the Math3 promoter, as well as to the promoter of GHRHR, a known target of Pit1 (Fig. 6E). Moreover, Math3 expression in the pituitary was significantly re- duced in Snell mice (Fig. 6C). Together, these data suggest that Math3 is a direct downstream target of Pit1 and uncover a developmentally regulated program whereby Math3 is repressed by Notch signaling and activated by 
A
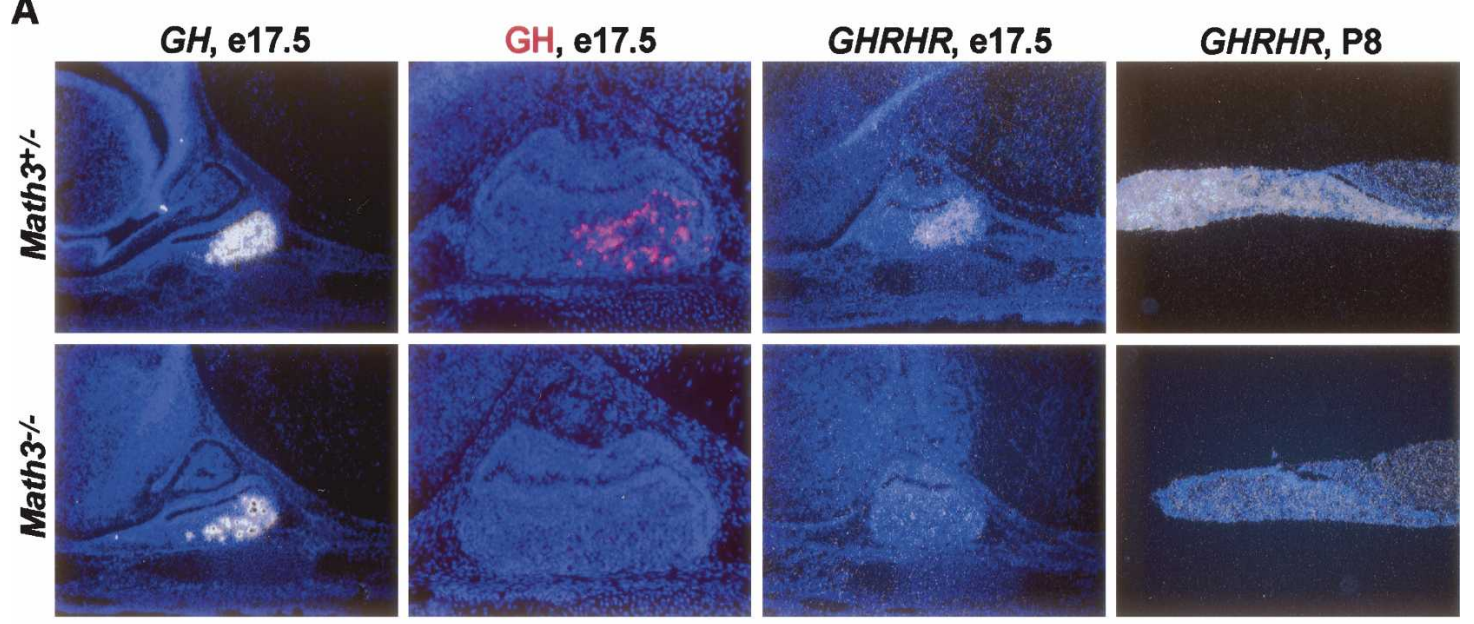

B
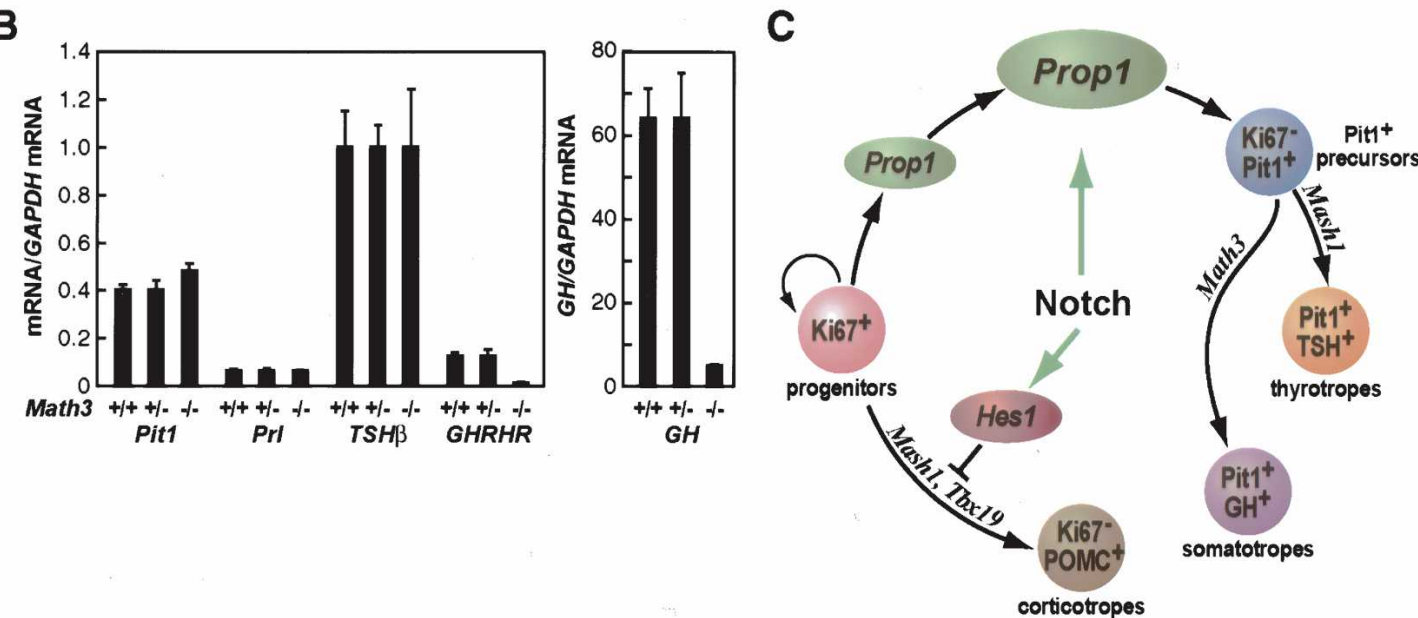

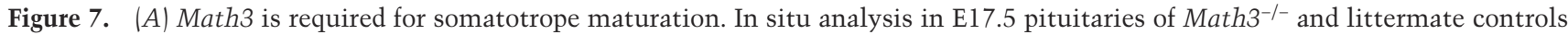
showed that somatotrope markers $G H$ and GHRHR are down-regulated in $\mathrm{Math}^{-/-}$. Immunofluorescence staining showed GH protein

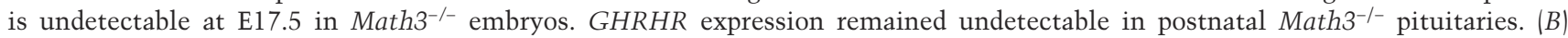
Quantitative RT-PCR of Pit1, Prl, TSH, GHRHR, and GH at E17.5 pituitaries showed significant and specific down-regulation of GH and GHRHR mRNA. (C) Model of Notch signaling in pituitary development. Notch-regulated Hes1 expression maintains self-renewal of the $\mathrm{Ki} 67^{+}$progenitor and prevents precocious corticotrope differentiation. Notch activity promotes Prop1 up-regulation at E12.5 and drives progenitors to adopt the fate of Pit $1^{+}$precursors. Mash1 and Math3 are required for proper development of thyrotropes and somatotropes, respectively.

the tissue-specific POU domain transcription factor Pit1. To our knowledge, in addition to Pit1 itself, Math3 is the first identified transcription factor regulated by Pit1.

Examination of pituitaries from P8 and P15 Math3 $3^{-/-}$ and wild-type littermates revealed a hypoplastic anterior pituitary with decreased numbers of somatotropes in Math3 ${ }^{-/-}$mice (data not shown). At E17.5, expression of $P O M C, L H \beta, P i t 1, \alpha G S U$, and TSH $\beta$ were not affected in Math $3^{-/-}$mice (Fig. 7B; data not shown). However, expression of GHRHR was almost completely abolished. The number of somatotropes expressing $G H$ was markedly decreased and, more strikingly, even fewer $\mathrm{GH}^{+}$ cells could be detected by immunostaining (data not shown), suggesting that Math3 is required in somatotropes for expression of GHRHR and GH at embryonic stages. Quantitative RT-PCR assay confirmed reduced levels of total GH mRNA in E17.5 $\mathrm{Math}^{-/-}$pituitaries, and further studies revealed no aberrant mRNA splicing of GH mRNA that might lead to defective GH protein synthesis (data not shown). The molecular mechanisms of the apparent discrepancy between the levels of $G H$ mRNA and protein have clear implications that will be the subject of future investigation. However, the block of somatotrope maturation in $\mathrm{Math}^{-/-}$mice is transient and recovers postnatally, because in P8 and P15 $\mathrm{Math}^{-/-}$pituitaries, $\mathrm{GH}^{+}$somatotropes, although obviously present in reduced cell number, were readily detectable by immunostaining, suggesting that Math3 is necessary for the proper onset of somatotrope specification. Expression of GHRHR, in contrast, remained minimal (Fig. 7A). The postnatal dwarf phenotype in Math $3^{-/-}$mice is likely attributable to the reduced number of somatotropes, as is observed in little mice, which harbor a point mutation in the GHRHR gene, rendering 
somatotropes incapable of responding to the hypothalamic trophic factor GHRH (Lin et al. 1993).

\section{Discussion}

The distinct cell types in the pituitary gland are generated in a temporal and spatial fashion. We have shown here that Notch activity operates in a precise temporal window during pituitary development. In early developmental stages, Notch signaling prevents premature differentiation by regulating Hes 1 expression. Perhaps more importantly, Notch signaling plays an essential role in controlling the lineage commitment of $\mathrm{Pit} 1^{+}$precursors, without which they would "switch" to an alternative cell fate. It does so, at least in large part, by directly regulating the expression of Prop1, a gene that is necessary for the genesis of $\mathrm{Pit}^{+}$precursors. In the late phases of pituitary development, however, Notch activity is dramatically attenuated in $\mathrm{Pit}^{+}$cells, in part because expression of a subset of bHLH factors that are otherwise negatively regulated by active Notch signaling is required for terminal differentiation of Pit1 lineages. One of these bHLH factors, Math3, is itself a downstream transcription target of Pit1, and is crucial for maturation and expansion of somatotropes through regulation of GHRHR expression.

\section{Notch activation controls formation of Pit1 precursors}

We have shown that both ligands and receptors of the Notch signaling pathway are expressed in proliferating progenitors in Rathke's pouch during early pituitary development. These cells transduce Notch signaling, as indicated by the loss of the Notch downstream effectors Hes1 and Hey1 when Notch activity is impeded by deletion of the Rbp-J gene. As cells within the Rathke's pouch exit the cell cycle, migrate ventrally and laterally out of the proliferative zone, and undergo lineage commitment and subsequent terminal differentiation, Notch signaling is turned off, and remaining Notch activity can be detected in only periluminal cells. Thus, the proliferative zone in pituitary development to a certain extent is similar to the ventricular zone in cerebral cortex development. In that system, Notch signaling is required to maintain the progenitor pools and inhibit neuronal differentiation (for review, see Yoon and Gaiano 2005). Due to the great inherent redundancy within the Delta/ Notch pathway and the pleiotropic defects associated with deletion of some of the Notch pathway components, blocking the Notch signaling results in premature differentiation and depletion of progenitor pools, precluding the analysis of Notch function in later-born cell lineage determination.

We have observed that in Rathke's pouch when $R b p-J$ is conditionally removed in progenitor cells, there is no immediate complete conversion of progenitor cells into post-mitotic corticotropes. Instead, the $\mathrm{Ki} 67^{+}$proliferative zone remains, which is capable of supporting the differentiation of gonadotropes and intermediate lobe melanotropes, implying that the progenitor cells retain a certain degree of pluripotency. However, Pit $1^{+}$precursors are almost completely missing, and instead are converted into corticotropes. Our data suggest a model in which Notch signaling controls the formation of diverse precursor subtypes from a progenitor pool. In this model, progenitors receiving no or only a short pulse of Notch signaling progress to the first-born cell lineage corticotropes, while those receiving longer durations of Notch signaling are suggested to undergo irreversible changes in gene expression and/or epigenetic status, such that they are competent to assume a later-born cell fate such as the Pit1 lineage precursor. Consistent with this model is our finding that Notch signaling is essential for the maintenance of Prop1 expression, providing a molecular mechanism underlying Notch signaling-dependent commitment of Pit1 precursors. This proposed model is likely generally employed in other developmental contexts. It has been shown that in the ventricular zone during mammalian cerebral cortex development, radial glial cells that have been temporarily subjected to Notch activation skip the early-born cell fate and differentiate into later-born upper-layer neurons (Mizutani and Saito 2005). In a detailed analysis of the kinetics and mechanisms of T-lineage differentiation in an in vitro culture system, continuous Notch signaling is obligatory to maintain development along the T-cell pathway (Taghon et al. 2005).

In addition to the well-characterized Notch targets Hes1 and Hey1, we have identified Prop1 as a Notch downstream target. However, their expression exhibits different dynamics, with Hes1 and Hey1 detectable at E9.5 in Rathke's pouch-indicative of active Notch signaling (Fig. 1; data not shown)-whereas Prop1 is not expressed until E11.5, suggesting that Notch activity is not sufficient to induce Prop1 expression (Sornson et al. 1996) and that initiation of Prop1 expression is independent of the Notch activity. However, the sustained expression of Prop1 is Notch-dependent. These data are consistent with the view that expression of Notch targets is dependent on the developmental status and appears to be target gene specific (Umesono et al. 2002; Anthony et al. 2005; Taghon et al. 2005). Premature expression of Prop1 in Rathke's pouch proves to be deleterious, leading to agenesis of the anterior pituitary gland, probably by inhibiting the endogenous function of Hesx1 (Dasen et al. 2001). Prolonged expression of Prop1 interferes with anterior pituitary cell differentiation (Cushman et al. 2001). Therefore, identifying the critical factors initiating Prop1 gene expression will provide further insights into the integration of the Notch pathway with other developmental programs. It has been reported recently that Prop1 is required for Notch2 protein expression in the pituitary (Raetzman et al. 2004). However, our in situ hybridization analyses of Prop1 ${ }^{-/-}$embryos showed that expression of Notch2 and Hes1, which is dependent on Notch signaling, is not significantly affected (Raetzman et al. 2004; our unpublished data), suggesting that deletion of Prop1 is not sufficient to downregulate Notch signaling during pituitary development. 
Down-regulation of Notch activity at a later stage is necessary for terminal differentiation

Notch signaling is down-regulated as cells exit the cell cycle and undergo terminal differentiation. We show that forced expression of NICD in $\mathrm{Pit}^{+}$post-mitotic cells is sufficient to prevent them from differentiating into hormone-producing cells, consistent with the role of Notch signaling in maintaining progenitor fate. These data highlight the importance of properly controlled Notch signaling during development and raise a fundamental question as to the regulation of Notch activity. Our expression data show that Notch activity in the pituitary is closely correlated with the expression of Notch receptors and ligands, implying a key component of this regulation would be their own expression, although other cellular mechanisms may also be involved (for review, see Schweisguth 2004). A recent study in Zebrafish retinal neurogenesis has demonstrated that a mutation in histone deacetylase 1 (Hdac 1) results in a defect in the transition from proliferating progenitor cells to post-mitotic neurons due to a failure to suppress Notch and Wnt pathways. Although this mechanism may be cell type specific, it suggests that transcription corepressors of Rbp-J may feedback to regulate Notch activity (Yamaguchi et al. 2005).

NICD expression in $\mathrm{Pit}^{+}$post-mitotic cells leads to induction of Hes1, Hes5, and Hey1 and repression of Mash1, NeuroD1, and Math3, implicating their functions in Pit1 lineage terminal differentiation. Indeed, Mash1 executes roles in differentiation of thyrotrope as well as corticotrope, melanotrope, and gonadotrope (our unpublished data). In this study, we demonstrate that Math3 is critical for maturation and expansion of somatotropes by regulating the expression of GHRHR. Thus, using the Pit1-NICD transgenic mouse as a genetic approach, we have uncovered bHLH factors as new components involved in Pitl lineage differentiation. Deletion of neither Mash1 nor Math3 alone account for the full spectrum of defects in the Pit1-NICD transgenic mouse and, therefore, whether they exert overlapping roles during pituitary development, as has been demonstrated in neurogenesis (Tomita et al. 2000), is the subject of ongoing investigation.

\section{Materials and methods}

Mice

A DNA-encoded mouse Notch1 intracellular domain, amino acids 1744-2183, was generously provided by Dr. R. Kopan (Washington University, St. Louis, MO) (Schroeter et al. 1998). A hemagglutinin (HA) tag was added at the C terminus of NICD cDNA. The Notch1-ICD-HA ORF was inserted between a rabbit $0.65-\mathrm{kb} \beta$-globin intron and a $0.63-\mathrm{kb}$ poly $(\mathrm{A})$ fragment of the human growth hormone gene at the $3^{\prime}$ end. The $15-\mathrm{kb}$ Pit1 promoter was inserted $5^{\prime}$ of this cassette. Transgenic mice were generated as described in Treier et al. (1998), and transgenic animals were genotyped by PCR using primers 5 -GCAACGT GCTGGTTATTGTGC-3' and 5'-CGGTCTGTCTGGTTGTG CAAGCTG-3'. The transgenic line was maintained on a CB6F1 background as a heterozygote. The male transgenic animals are dwarf and fertile while the females are dwarf and sterile. Other mice used in this study-floxed Rbp-J, Hes1 knockout, and Math3 knockout-have been described previously (Ishibashi et al. 1995; Tomita et al. 2000; Tanigaki et al. 2002). The $R b p$-floxed/floxed, Pitx1-Cre mutant embryos were obtained by crossing $R b p$ - floxed/floxed $^{\text {mice with mice heterozygeous for }}$ floxed Rbp-I and Pitx1-Cre (Olson et al. 2006).

\section{In situ hybridization and immunofluorescence}

In situ hybridization and immunofluorescence were carried out as previously described (Simmons et al. 1990). Mouse embryos from E9.5 to E17.5 were fixed in $10 \%$ neutral formalin, penetrated with $20 \%$ sucrose in PBS, and embedded in OCT compound. Serial $16-\mu \mathrm{m}$ sections were hybridized with ${ }^{35} \mathrm{~S}$-labeled antisense RNA probes. The probes used in this study were either purchased as EST clones from ATCC or generated by RTPCR from various tissues and verified by sequencing. For immunofluorescence staining, the sections were boiled for $10 \mathrm{~min}$ in $10 \mathrm{mM}$ citrate buffer ( $\mathrm{pH}$ 6.0) to retrieve antigens and stained with mouse mAbs against the HA tag (Babco, 1:400), Ki-67 (Pharmingen, 1:50), BrdU (ICN Biomedicals, 1:20), rabbit polyclonal antibodies against GH (DAKO, 1:200), TSH (National Hormone and Pituitary Program, National Institute of Diabetes and Digestive and Kidney Diseases, rabbit, 1:400), ACTH (Sigma, 1:100), and Pit-1 (1:200). Secondary peroxidase, Alexa Fluor 488-, and Alexa Fluor 594-conjugated antibodies were from Jackson ImmunoResearch and Molecular Probes. Slides were coverslipped in Vectashield Mounting Medium with DAPI (Vector Laboratories). The results were analyzed on a Zeiss Axioplan2 microscope with a Hamamatsu camera, and pictures were superimposed in Adobe Photoshop.

\section{EMSA, transfection, ChIP, and quantitative PCR}

EMSA experiments were performed as previously described (Reizis and Leder 2002). Double-stranded oligonucleotides were labeled with $\gamma_{-}{ }^{32} \mathrm{P}$-ATP. Rbp-J was transcribed and translated using the TNT Quick Coupled Transcription/Translation Systems (Promega). In vitro translated proteins were incubated with $1 \times$ binding buffer $(25 \mathrm{mM}$ Tris at $\mathrm{pH} 7.5,50 \mathrm{mM} \mathrm{NaCl}, 1$ mM EDTA, 1 mM DTT, 5\% glycerol), DNA competitors, and 1 $\mu \mathrm{g}$ of poly-dIdC for $15 \mathrm{~min}$ on ice prior to adding probe. Probe was added to the reaction and allowed to bind for $20 \mathrm{~min}$ at room temperature, and then protein-DNA complexes were resolved by electrophoresis. Oligonucleotides used for EMSA are 5'-CTTGAGCTCGTGGGAAAGGCTTGCC-3', 5'-GGCAAG CCTTTCCCACGAGCTCAAG-3' (Prop1 intron); 5'-CTTGA GCTCGTGaacAAGGCTTGCC-3', 5'-GGCAAGCCTTgttCA CGAGCTCAAG-3', (Prop1 intron with mutations); and 5'AAACACGCCGTGGGAAAAAATTTGG-3', 5' -CCAAATT TTTTCCCACGGCGTGTTT-3' (Rbp-J-binding site from Epstein-Barr virus $\mathrm{C}$ promoter region). Transient transfection of pituitary cell lines GC and GHFT1 using SuperFect (Qiagen) or Lipofectamine 2000 (Invitrogen) was performed according to the manufacturers' instructions. ChIPs were performed as previously described (Wang et al. 2006) with some modifications. The pituitaries were dissected from wild-type E12.5 embryos or adult mice and cross-linked with $2 \%$ formaldehyde for $20 \mathrm{~min}$ at room temperature. Aliquots $(1 \mu \mathrm{L})$ of $30 \mu \mathrm{L}$ of purified DNA fragments were analyzed by quantitative real-time PCR. For RT-PCR analysis, total RNA was isolated from dissected pituitary using the RNeasy Mini Kit (Qiagen), and cDNA was synthesized using SuperScript II (Invitrogen). Quantitative RT- 
PCR using Sybr Green was performed on an Mx3000P QPCR System (Stratagene). Primers sequences are available on request.

\section{Acknowledgments}

We thank T. Honjo for the floxed Rbp-J mice, R. Kopan for the NICD cDNA and Hes1-Luciferase reporter constructs, and R.J. McEvilly and C.R. Lin for critical reading of the manuscript and suggestions. We thank the UCSD transgenic core facility for assistance in generating transgenic mice, $\mathrm{H}$. Taylor for animal husbandry, C. Nelson for cell culture assistance, and J. Hightower and M. Fisher for figure and manuscript preparation. X.Z. was supported by National Institutes of Health Individual National Research Service Award 5F32NS10819. M.G.R. is an investigator with the Howard Hughes Medical Institute. This research was supported by a grant from the NIDDK to M.G.R.

\section{References}

Anthony, T.E., Mason, H.A., Gridley, T., Fishell, G., and Heintz, N. 2005. Brain lipid-binding protein is a direct target of Notch signaling in radial glial cells. Genes \& Dev. 19: 1028-1033.

Artavanis-Tsakonas, S., Rand, M.D., and Lake, R.J. 1999. Notch signaling: Cell fate control and signal integration in development. Science 284: 770-776.

Burns, C.E., Traver, D., Mayhall, E., Shepard, J.L., and Zon, L.I. 2005. Hematopoietic stem cell fate is established by the Notch-Runx pathway. Genes \& Dev. 19: 2331-2342.

Camper, S.A., Saunders, T.L., Katz, R.W., and Reeves, R.H. 1990. The Pit-1 transcription factor gene is a candidate for the murine Snell dwarf mutation. Genomics 8: 586-590.

Chesnokova, V. and Melmed, S. 2002. Minireview: Neuro-immuno-endocrine modulation of the hypothalamic-pituitary-adrenal (HPA) axis by gp130 signaling molecules. Endocrinology 143: 1571-1574.

Chu, J. and Bresnick, E.H. 2004. Evidence that C promoterbinding factor 1 binding is required for Notch-1-mediated repression of activator protein-1. J. Biol. Chem. 279: 1233712345.

Crosnier, C., Vargesson, N., Gschmeissner, S., Ariza-McNaughton, L., Morrison, A., and Lewis, J. 2005. Delta-Notch signalling controls commitment to a secretory fate in the zebrafish intestine. Development 132: 1093-1104.

Cushman, L.J., Watkins-Chow, D.E., Brinkmeier, M.L., Raetzman, L.T., Radak, A.L., Lloyd, R.V., and Camper, S.A. 2001. Persistent Prop1 expression delays gonadotrope differentiation and enhances pituitary tumor susceptibility. Hum. Mol. Genet. 10: 1141-1153.

Dasen, J.S. and Rosenfeld, M.G. 2001. Signaling and transcriptional mechanisms in pituitary development. Annu. Rev. Neurosci. 24: 327-355.

Dasen, J.S., O'Connell, S.M., Flynn, S.E., Treier, M., Gleiberman, A.S., Szeto, D.P., Hooshmand, F., Aggarwal, A.K., and Rosenfeld, M.G. 1999. Reciprocal interactions of Pit1 and GATA2 mediate signaling gradient-induced determination of pituitary cell types. Cell 97: 587-598.

Dasen, J.S., Barbera, J.P., Herman, T.S., Connell, S.O., Olson, L., Ju, B., Tollkuhn, J., Baek, S.H., Rose, D.W., and Rosenfeld, M.G. 2001. Temporal regulation of a paired-like homeodomain repressor/TLE corepressor complex and a related activator is required for pituitary organogenesis. Genes \& Dev. 15: 3193-3207.

Duncan, A.W., Rattis, F.M., DiMascio, L.N., Congdon, K.L., Pa- zianos, G., Zhao, C., Yoon, K., Cook, J.M., Willert, K., Gaiano, N., et al. 2005. Integration of Notch and Wnt signaling in hematopoietic stem cell maintenance. Nat. Immunol. 6: 314-322.

Ericson, J., Norlin, S., Jessell, T.M., and Edlund, T. 1998. Integrated FGF and BMP signaling controls the progression of progenitor cell differentiation and the emergence of pattern in the embryonic anterior pituitary. Development 125: 1005-1015.

Fre, S., Huyghe, M., Mourikis, P., Robine, S., Louvard, D., and Artavanis-Tsakonas, S. 2005. Notch signals control the fate of immature progenitor cells in the intestine. Nature 435: 964-968.

Gage, P.J., Brinkmeier, M.L., Scarlett, L.M., Knapp, L.T., Camper, S.A., and Mahon, K.A. 1996. The Ames dwarf gene, $\mathrm{df}$, is required early in pituitary ontogeny for the extinction of Rpx transcription and initiation of lineage-specific cell proliferation. Mol. Endocrinol. 10: 1570-1581.

Gaiano, N., Nye, J.S., and Fishell, G. 2000. Radial glial identity is promoted by Notch1 signaling in the murine forebrain. Neuron 26: 395-404.

Grandbarbe, L., Bouissac, J., Rand, M., Hrabe de Angelis, M., Artavanis-Tsakonas, S., and Mohier, E. 2003. Delta-Notch signaling controls the generation of neurons/glia from neural stem cells in a stepwise process. Development 130: 13911402.

Herzog, W., Zeng, X., Lele, Z., Sonntag, C., Ting, J.W., Chang, C.Y., and Hammerschmidt, M. 2003. Adenohypophysis formation in the zebrafish and its dependence on sonic hedgehog. Dev. Biol. 254: 36-49.

Hitoshi, S., Alexson, T., Tropepe, V., Donoviel, D., Elia, A.J., Nye, J.S., Conlon, R.A., Mak, T.W., Bernstein, A., and van der Kooy, D. 2002. Notch pathway molecules are essential for the maintenance, but not the generation, of mammalian neural stem cells. Genes \& Dev. 16: 846-858.

Irvine, K.D. 1999. Fringe, Notch, and making developmental boundaries. Curr. Opin. Genet. Dev. 9: 434-441.

Ishibashi, M., Ang, S.L., Shiota, K., Nakanishi, S., Kageyama, R., and Guillemot, F. 1995. Targeted disruption of mammalian hairy and Enhancer of split homolog-1 (HES-1) leads to upregulation of neural helix-loop-helix factors, premature neurogenesis, and severe neural tube defects. Genes \& Dev. 9: 3136-3148.

Iso, T., Kedes, L., and Hamamori, Y. 2003. HES and HERP families: Multiple effectors of the Notch signaling pathway. $J$. Cell. Physiol. 194: 237-255.

Japon, M.A., Rubinstein, M., and Low, M.J. 1994. In situ hybridization analysis of anterior pituitary hormone gene expression during fetal mouse development. J. Histochem. Cytochem. 42: 1117-1125.

Krebs, L.T., Iwai, N., Nonaka, S., Welsh, I.C., Lan, Y., Jiang, R., Saijoh, Y., O'Brien, T.P., Hamada, H., and Gridley, T. 2003 Notch signaling regulates left-right asymmetry determination by inducing Nodal expression. Genes \& Dev. 17: 12071212.

Lai, E.C. 2004. Notch signaling: Control of cell communication and cell fate. Development 131: 965-973.

Lamolet, B., Pulichino, A.M., Lamonerie, T., Gauthier, Y., Brue, T., Enjalbert, A., and Drouin, J. 2001. A pituitary cell-restricted $\mathrm{T}$ box factor, Tpit, activates POMC transcription in cooperation with Pitx homeoproteins. Cell 104: 849-859.

Lamolet, B., Poulin, G., Chu, K., Guillemot, F., Tsai, M.J., and Drouin, J. 2004. Tpit-independent function of Neurod1( $\beta 2)$ in pituitary corticotroph dfferentiation. Mol. Endocrinol. 18: 995-1003.

Lewis, J. 1998. Notch signalling and the control of cell fate 
choices in vertebrates. Semin. Cell Dev. Biol. 9: 583-589.

Li, S., Crenshaw III, E.B., Rawson, E.J., Simmons, D.M., Swanson, L.W., and Rosenfeld, M.G. 1990. Dwarf locus mutants lacking three pituitary cell types result from mutations in the POU-domain gene pit-1. Nature 347: 528-533.

Lin, S.C., Lin, C.R., Gukovsky, I., Lusis, A.J., Sawchenko, P.E., and Rosenfeld, M.G. 1993. Molecular basis of the little mouse phenotype and implications for cell type-specific growth. Nature 364: 208-213.

Liu, J., Lin, C., Gleiberman, A., Ohgi, K.A., Herman, T., Huang, H.P., Tsai, M.J., and Rosenfeld, M.G. 2001. Tbx19, a tissueselective regulator of POMC gene expression. Proc. Natl. Acad. Sci. 98: 8674-8679.

Meador-Woodruff, J.H., Mansour, A., Bunzow, J.R., Van Tol, H.H., Watson Jr., S.J., and Civelli, O. 1989. Distribution of D2 dopamine receptor mRNA in rat brain. Proc. Nat1. Acad. Sci. 86: 7625-7628.

Mizutani, K. and Saito, T. 2005. Progenitors resume generating neurons after temporary inhibition of neurogenesis by Notch activation in the mammalian cerebral cortex. Development 132: 1295-1304.

Ohuchi, H., Hori, Y., Yamasaki, M., Harada, H., Sekine, K., Kato, S., and Itoh, N. 2000. FGF10 acts as a major ligand for FGF receptor 2 IIIb in mouse multi-organ development. Biochem. Biophys. Res. Commun. 277: 643-649.

Olson, L.E., Tollkuhn, J., Scafoglio, C., Krones, A., Zhang, J., Ohgi, K.A., Wu, W., Taketo, M.M., Kemler, R., Grosschedl, R., et al. 2006. A homeodomain-mediated mechanism for distinct $\beta$-catenin-dependent switching events dictating cell lineage determination. Cell 125: 593-605.

Pulichino, A.M., Vallette-Kasic, S., Tsai, J.P., Couture, C., Gauthier, Y., and Drouin, J. 2003. Tpit determines alternate fates during pituitary cell differentiation. Genes \& Dev. 17: 738-747.

Raetzman, L.T., Ross, S.A., Cook, S., Dunwoodie, S.L., Camper, S.A., and Thomas, P.Q. 2004. Developmental regulation of Notch signaling genes in the embryonic pituitary: Prop1 deficiency affects Notch2 expression. Dev. Biol. 265: 329-340.

Raya, A., Kawakami, Y., Rodriguez-Esteban, C., Buscher, D., Koth, C.M., Itoh, T., Morita, M., Raya, R.M., Dubova, I., Bessa, J.G., et al. 2003. Notch activity induces Nodal expression and mediates the establishment of left-right asymmetry in vertebrate embryos. Genes \& Dev. 17: 1213-1218.

Reizis, B. and Leder, P. 2002. Direct induction of T lymphocytespecific gene expression by the mammalian Notch signaling pathway. Genes \& Dev. 16: 295-300.

Revest, J.M., Spencer-Dene, B., Kerr, K., De Moerlooze, L., Rosewell, I., and Dickson, C. 2001. Fibroblast growth factor receptor 2-IIIb acts upstream of Shh and Fgf4 and is required for limb bud maintenance but not for the induction of Fgf8, Fgf10, Msx1, or Bmp4. Dev. Biol. 231: 47-62.

Rizzoti, K. and Lovell-Badge, R. 2005. Early development of the pituitary gland: Induction and shaping of Rathke's pouch. Rev. Endocr. Metab. Disord. 6: 161-172.

Sbrogna, J.L., Barresi, M.J., and Karlstrom, R.O. 2003. Multiple roles for Hedgehog signaling in zebrafish pituitary development. Dev. Biol. 254: 19-35.

Schroeter, E.H., Kisslinger, J.A., and Kopan, R. 1998. Notch-1 signalling requires ligand-induced proteolytic release of intracellular domain. Nature 393: 382-386.

Schweisguth, F. 2004. Notch signaling activity. Curr. Biol. 14: R129-R138.

Sheng, H.Z. and Westphal, H. 1999. Early steps in pituitary organogenesis. Trends Genet. 15: 236-240.

Simmons, D.M., Voss, J.W., Ingraham, H.A., Holloway, J.M., Broide, R.S., Rosenfeld, M.G., and Swanson, L.W. 1990. Pi- tuitary cell phenotypes involve cell-specific Pit-1 mRNA translation and synergistic interactions with other classes of transcription factors. Genes \& Dev. 4: 695-711.

Sornson, M.W., Wu, W., Dasen, J.S., Flynn, S.E., Norman, D.J., O'Connell, S.M., Gukovsky, I., Carriere, C., Ryan, A.K., Miller, A.P., et al. 1996. Pituitary lineage determination by the Prophet of Pit-1 homeodomain factor defective in Ames dwarfism. Nature 384: 327-333.

Taghon, T.N., David, E.S., Zuniga-Pflucker, J.C., and Rothenberg, E.V. 2005. Delayed, asynchronous, and reversible Tlineage specification induced by Notch/Delta signaling. Genes \& Dev. 19: 965-978.

Takuma, N., Sheng, H.Z., Furuta, Y., Ward, J.M., Sharma, K., Hogan, B.L., Pfaff, S.L., Westphal, H., Kimura, S., and Mahon, K.A. 1998. Formation of Rathke's pouch requires dual induction from the diencephalon. Development 125: 48354840.

Tanigaki, K., Han, H., Yamamoto, N., Tashiro, K., Ikegawa, M., Kuroda, K., Suzuki, A., Nakano, T., and Honjo, T. 2002. Notch-RBP-J signaling is involved in cell fate determination of marginal zone B cells. Nat. Immunol. 3: 443-450.

Tomita, K., Moriyoshi, K., Nakanishi, S., Guillemot, F., and Kageyama, R. 2000. Mammalian achaete-scute and atonal homologs regulate neuronal versus glial fate determination in the central nervous system. EMBO J. 19: 5460-5472.

Treier, M., Gleiberman, A.S., O'Connell, S.M., Szeto, D.P., McMahon, J.A., McMahon, A.P., and Rosenfeld, M.G. 1998. Multistep signaling requirements for pituitary organogenesis in vivo. Genes \& Dev. 12: 1691-1704.

Treier, M., O'Connell, S., Gleiberman, A., Price, J., Szeto, D.P., Burgess, R., Chuang, P.T., McMahon, A.P., and Rosenfeld, M.G. 2001. Hedgehog signaling is required for pituitary gland development. Development 128: 377-386.

Umesono, Y., Hiromi, Y., and Hotta, Y. 2002. Context-dependent utilization of Notch activity in Drosophila glial determination. Development 129: 2391-2399.

van Es, J.H., van Gijn, M.E., Riccio, O., van den Born, M., Vooijs, M., Begthel, H., Cozijnsen, M., Robine, S., Winton, D.J., Radtke, F., et al. 2005. Notch $/ \gamma$-secretase inhibition turns proliferative cells in intestinal crypts and adenomas into goblet cells. Nature 435: 959-963.

Wang, Z., Qi, C., Krones, A., Woodring, P., Zhu, X., Reddy, J.K., Evans, R.M., Rosenfeld, M.G., and Hunter, T. 2006. Critical roles of the p160 transcriptional coactivators p/CIP and SRC-1 in energy balance. Cell Metab. 3: 111-122.

Ward, R.D., Raetzman, L.T., Suh, H., Stone, B.M., Nasonkin, I.O., and Camper, S.A. 2005. Role of PROP1 in pituitary gland growth. Mol. Endocrinol. 19: 698-710.

Watkins-Chow, D.E. and Camper, S.A. 1998. How many homeobox genes does it take to make a pituitary gland? Trends Genet. 14: 284-290.

Yamaguchi, M., Tonou-Fujimori, N., Komori, A., Maeda, R., Nojima, Y., Li, H., Okamoto, H., and Masai, I. 2005. Histone deacetylase 1 regulates retinal neurogenesis in zebrafish by suppressing Wnt and Notch signaling pathways. Development 132: 3027-3043.

Yoon, K. and Gaiano, N. 2005. Notch signaling in the mammalian central nervous system: Insights from mouse mutants. Nat. Neurosci. 8: 709-715. 


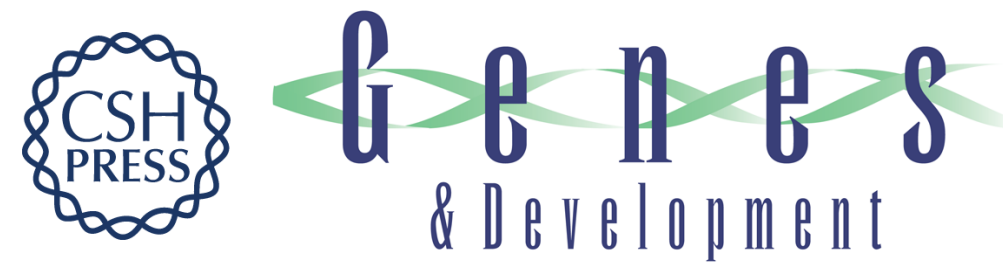

\section{Sustained Notch signaling in progenitors is required for sequential emergence of distinct cell lineages during organogenesis}

Xiaoyan Zhu, Jie Zhang, Jessica Tollkuhn, et al.

Genes Dev. 2006, 20:

Access the most recent version at doi:10.1101/gad.1444706

Supplemental http://genesdev.cshlp.org/content/suppl/2006/09/19/20.19.2739.DC1
Material

References This article cites 60 articles, 25 of which can be accessed free at:

http://genesdev.cshlp.org/content/20/19/2739.full.html\#ref-list-1

License

Email Alerting

Receive free email alerts when new articles cite this article - sign up in the box at the top

Service

right corner of the article or click here.

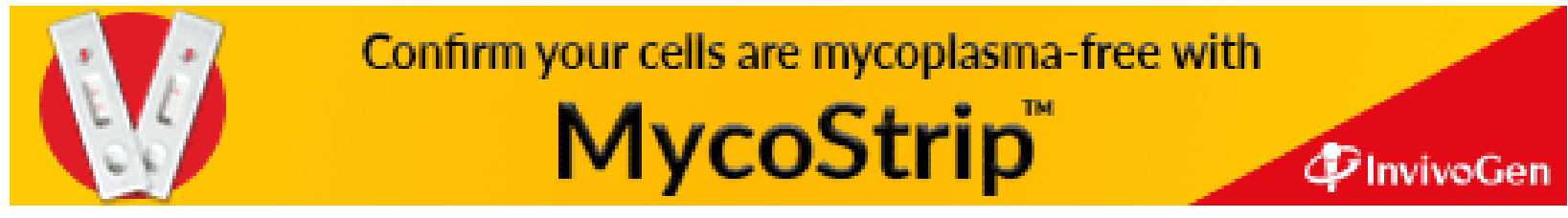

